\title{
Optimal Reserves and Short Term Interest Rates in a Model of Bank Runs
}

\author{
Geethanjali Selvaretnam
}

December 14, 2005

\begin{abstract}
Banks can fail because of bad economic fundamentals, and/or general panic withdrawals by depositors who feel the bank does not have sufficient reserves to meet the demand. This paper attempts to find the optimal reserve level and early returns the banks should decide on.

If the reserve policy of the bank is transparent, it is found that more reserves have to be put aside over and above the real need, and this inefficiency increases with the proportion of impatient agents. It is also found that the optimal early return is lower than the first-best. The model recommends that when reserve policy is transparent there is no need for regulation.

However, if reserve policy is not transparent, the model recommends regulation for both reserves and early returns. This is because of the moral hazard problem, the banks would keep lower reserves and offer higher early returns than what maximises depositor welfare.
\end{abstract}

JEL Classifications: D82, G21,G28

Key Words: Optimal reserves, short term interest rate, Bank runs, global game, Unique equilibrium. 


\section{Introduction}

Banks collect money from individuals as deposits, and invest in long-term projects while keeping part of the deposits as reserves. Because banks are trying to finance long-term projects with short-term liabilities, they become vulnerable to bank runs. USA went through this experience during 1890-1908 and 1929-1933 when there were 21 and 5 bank-panics respectively. Lindgren, Garcia and Saal(1996) state that $73 \%$ of the IMF's member countries suffered some form of banking crisis between 1980-1996. More recently in the 21st century we have the crisis in Argentina and Uruguay.

Banking crises can happen because of inefficient management, bad economic conditions or fraud. In addition to that, banks can also fail because of general panic that prompt the depositors to withdraw too much, forcing the banks to shutdown. There is empirical evidence for both these causes. ${ }^{1}$

Various models have been put forward trying to explain bank runs. The Diamond and Dybvig (1983) model, which is considered a pioneering paper in bank runs, shows that bank runs are caused by self-fulfilling beliefs of depositors. Their model has two equilibria: the bank-run equilibrium and the no bank-run equilibrium.

Following the Diamond and Dybvig's sun-spot explanation given to bank runs, there were many models that showed that bank runs were actually information-based - i.e. they said that depositors' decision to withdraw was because of the information they receive about expected returns: ${ }^{2}$ Theoretically and empirically it has been shown that bank runs are caused by both self-fulfilling beliefs and information about returns.

The existence of multiple equilibria in the Diamond and Dybvig model made it difficult for useful analysis and comparison of policies. However a significant break through in this strand of literature has now been made. Goldstein and Pauzner (2005) establish a unique equilibrium in a model based on global games introduced by Carlson and Van Damme (1993) and extended by Morris and Shin (1998). Everything that

\footnotetext{
${ }^{1}$ Demirgue - Kunt and Detragiache (1998), Kaminsky and Reinhart (1999), Gorton (1988) have done studies on adverse banking conditions triggering off banking crises. Radlet and Sachs (1998), having examined the characteristics of financial crises in Mexico-1994/5, Argentina-1995 and East Asia-1997, note that one of the reasons was the element of self-fulfilling crisis.

${ }^{2}$ Gorton 1985 (1988), Jacklin and Bhattacharya (1988), Alonso (1996), Loewy (1998), Cooper and Ross (1998), Bougheas (1999) are some of the main ones. Chari and Jegannathan (1988) developed a model where the rational expectation equilibrium is a combination of fundamental bank-runs and speculative bank runs.
} 
has an influence on the uncertain return of the long term project is captured by the economic fundamental. If agents receive noisy signals about the economic fundamental (as opposed to the common knowledge of the fundamental in the Diamond and Dybvig model), a threshold fundamental exists, below which there would be a bank-run and above which there will not be a bank-run. Bank runs continue to be driven by bad expectations that others would withdraw, but the belief itself is uniquely determined by the threshold value. They use this unique equilibrium to compute the probability of bank runs and show that it increases with the proportion of impatient agents and return given to early withdrawers.

Modelling bank runs using noisy signals allows for withdrawals to be based both on information and self-fulfilling beliefs. It further gives a unique equilibrium which enables us to arrive at important policy decisions. The model is closest to the Goldstein and Pauzner (2005) set up. The crucial difference is in the question it addresses. Using the unique equilibrium this paper attempts to throw some light on two important decisions that a bank has to make: reserves it has to keep and short term interest it has to offer early withdrawers.

A bank can fail because of insolvency or illiquidity. The outcome of the economic fundamental cannot be controlled by that bank. But the bank should try to avoid failure due to illiquidity by keeping adequate reserves. Even though the depositors are concerned about the bank's profitability, if they feel that the bank does not have enough liquidity, there will be a panic-run. Higher the early return, higher the incentive for people to withdraw early. The more early withdrawals that is anticipated, the more should be the reserves to meet the demand. Keeping reserves reduces the earning capacity of the bank but increases the availability of money to meet the demand for early withdrawals. Therefore it is important that a right balance is kept between earning in the long-term and having sufficient liquidity to meet the demand in the short-term.

Here, the banks face the possibility of depositors withdrawing because of genuine liquidity shocks as well as self-fulfilling beliefs. A fixed proportion of depositors have to withdraw early because they are hit by a liquidity shock. These depositors receive a liquidity shock and have to definitely withdraw early. In addition to that, the depositors also observe a noisy signal about the bank's future earning potential. If they expect to lose out by waiting, even those who are not hit by the liquidity shock will withdraw early. The bank is a profit maximiser, but operating in a competitive 
environment.

We look at this problem under two scenarios: scenario 1 is when the level of reserves that the bank keeps can be observed by the depositors and scenario 2 is when the reserve policy of the bank is not transparent. The key difference in the outcomes of the two scenarios is that we find that when reserves is transparent there is no need for regulation whereas when it is not transparent there is a need for regulation, both for reserves and early returns. There is also support for regulation in other papers where it is predicted that banks would not keep sufficient reserves if it is not observable. ${ }^{3}$

\section{$1.1 \quad$ Main Results}

When the reserve policy is transparent (scenario 1), because the bank is operating in a competitive environment, the bank seeks to maximise the expected utility of the depositors because it operates in a competitive market. The model predicts that the bank can find an optimal reserve level and an early return rate to maximise expected utility of depositors.

First we look at the first-best scenario where the bank can observe whether the depositors are patient or impatient and therefore would only meet the demand of those who are impatient. The first-best reserve level would be just enough to meet the demand of the impatient agents.

In the next section, the bank cannot distinguish between the patient and impatient depositors. It is found that the optimal level of reserves and the early return that the bank chooses, increase with the proportion of impatient agents and reduce with the long term earning potential. These results are quite intuitive. When the agents face a higher probability of being hit by a liquidity shock, they will wwant a higher early return to maximise their expected utility. In order to that, the reserve level should be higher and also, the agents will need more reassurance of sufficient reserves.

An interesting result is that the early return that maximises expected utility is always below one as long as some agents are impatient. This means that even if agents withdraw because they are genuinely hit by a liquidity shock, they are penalised and given less than what they invested! Comparing the results with the first-best scenario

\footnotetext{
${ }^{3}$ Cothren (1987), Bhattacharya and Boot (1998). According to Clouse and Dow (2002), banks adjust their reserves to keep the probability of failure due to liquidity constant. Ringborn et al (2004) show that the optimal reserves reduces with the earning potential of the investment and increases with the depositors' expected need to withdraw and the correlation of liquidity shocks among depositors.
} 
the early return in the first-best scenario is higher. This is because in the first-best case, the bank keeps reserves only to serve the impatient depositors and does not have to use early return as an instrument to dissuade patient agents from withdrawing early. Even though a higher early return provides more insurance against liquidity shocks, it increases the risk of bank runs by providing an incentive for early withdrawal and reducing the long-term earning potential of the bank. This paper shows that it is optimal to actually penalise those who withdraw early even if they are genuinely hit by a liquidity shock. This result endorses the results obtained by Goldstein and Pauzner as well.

An important result of this paper is that the optimal choice of reserves and early return gives a threshold such that, in the existence of impatient agents, some patient agents would also want to withdraw early. The bank keeps reserves over and above what is needed to meet the demand of those who are genuinely hit by the liquidity shock. This inefficiency of keeping reserves to serve patient agents increases with the proportion of impatient agents.

The model predicts that the probability of bank runs increases with early returns, but reduces with reserves. If early return is high, agents get higher return when they withraw early and there is more probability that the bank would crash because of insufficient reserves. On the other hand, when reserves are high, the agents have the confidence that the bank will have sufficient reserves to survive till the next period. The model also points out that when the expected utility of the depositors is maximised, the bank would choose reserves and early returns where there will be a positive probability of bank runs.

Policy makers should take note of these findings. If depositors can observe the reserves and there is competition in the market, the banks would choose reserves and early returns to maximise the depositors' expected utility. Therefore this model suggests there is no need for regulation.

The analysis under scenario 2 when the reserve policy of the bank is not transparent however, recommends that there is indeed a role for regulation. The results in scenario 1 was driven by the fact that the reserves kept by the bank was public knowledge. It is a reasonable assumption that the depositors will not have this information when they make decisions.

The results predict that the bank would then keep reserves just sufficient to meet the demand of those hit by the liquidity shock. The level of reserves is lower if it 
cannot be observed than what would be put aside if it cannot be observed. Also, if reserves cannot be observed, the chosen level of reserves makes the expected utility lower and the probability of bank runs higher.

Another interesting result is also obtained when the bank's reserve policy cannot be observed. If we allow the banks to choose the early return that is offered to those withdrawing early, the bank would choose it to be inefficiently high to attract customers in the competitive market. Early return is higher when reserves cannot be observed than what would be chosen if the level of reserves was transparent. This is also detrimental for the financial stability of the country, because the chosen early return pushes up the probability of bank runs.

Therefore the regulators have important roles to play when level of reserves cannot be observed. The level of reserves as well as the early return should be regulated. They should keep a tab on the upper bound of the early return that a bank can offer and the minimum level of reserves that is put aside to meet early withdrawal.

The rest of the paper is organised as follows: First we look at scenario 1 where the level of reserves is transparent. Here the model is set up in section 2, followed by section 3 where the unique equilibrium is established. Section 4 looks at the first-best scenario and at the case where the bank cannot distinguish between the two types. Then we look at scenario 2 where the level of reserves is not transparent. The model is set up in section 5 , followed by a discussion about the unique equilibrium. Section 7 discusses the level of reserves that is chosen, comparing when the reserves can be observed and when it is private information. Section 8 analyses what happens if early returns can also be chosen by the bank. Section 9 concludes.

\section{Scenario I - Transparent Reserve Policy}

\section{The Model}

The model has three periods $\left(t_{0}, t_{1}, t_{2}\right)$. There is a continuum $[0,1]$ of agents who are the depositors, and a bank which operates in a competitive market. All the agents have endowments of one unit at the beginning of $t_{0}$. Consumption happens only in periods $t_{1}$ and $t_{2}$. Agents can be of two types - either patient or impatient. They learn their types at the beginning of $t_{1}$ which is their private information. Impatient agents can derive utility only by consuming in $t_{1}$ and patient agents can derive utility 
from consuming in either $t_{1}$ or $t_{2}$. All agents are identical and risk averse, and each agent's utility function is increasing, twice continuously differentiable, strictly concave and has a relative risk aversion coefficient of $0<\frac{-c u^{\prime \prime}(c)}{u^{\prime}(c)}<1$. More specifically, their utility functions are given by $u=c_{1}^{\alpha}$ for the impatient agents and $u=\left(c_{1}+c_{2}\right)^{\alpha}$ for the patient agents where $\alpha \in(0,1)$ and $c_{t}$ is the return the agent gets in period $t$.

Expected returns from investing in a bank are high enough such that the agents will invest their endowments of one unit in the bank at date $t_{0}$. The bank keeps proportion $\rho$ as reserves, and invests the balance $(1-\rho)$ in a long term risky project. Those agents who withdraw early in $t_{1}$ will receive a return of $r$ (early return) that is chosen by the bank. If the demand for withdrawals in $t_{1}$ exceeds the reserves $\rho$, the bank has to liquidate the long term project at a very small value (close to zero) and therefore will have to close down in $t_{1}$ unless the bank is in the upper dominant region, which is explained later). If the bank crashes in $t_{1}$ those who waited without withdrawing early will receive nothing.

Each unit that is invested in the long term project in $t_{0}$ realizes $\theta$ at date $t_{2}$. The fundamental $\theta$ captures everything that will affect the return of the investment such as the economic and political environment that influence the success of the project etc. In $t_{2}$ everything that is available is distributed equally among all those depositors who did not withdraw early. The bank operates in a competitive environment and therefore its objective is to maximise the expected utility of the depositors subject to zero profits. If not, the bank will lose all the customers to banks that offer a slightly better deal.

The economic fundamental $\theta$ is uncertain and is drawn from a uniform distribution on $[\underline{\theta}, \bar{\theta}]$ where $\underline{\theta}=0$ and $\bar{\theta}>0$ and large. At the beginning of $t_{1} \theta$ is realised and each agent $i$ observes a noisy signal $\theta_{i}=\theta+\epsilon_{i}$ of the economic fundamental $\theta$. The noise $\epsilon_{i}$ is uniformly and independently distributed among the depositors with support $[-e,+e]$. Once the agents observe the signal, they will decide whether to withdraw in $t_{1}$ or wait till $t_{2}$. This decision is based on their beliefs about $\theta$ that is realised and the number of agents who would withdraw in $t_{1}$. The signal received by each agent can be interpreted as the information about the return in $t_{2}$ that is privately available to them and their ability to interpret them. Higher the $\theta_{i}$ higher is agent $i$ 's own expectation of the return on the investment. In addition to that, when an agent receives a high signal he also expects the other agents to have received a higher signal and therefore is less likely to withdraw. 
At the beginning of $t_{1}$, proportion $\lambda$ of the depositors receive a liquidity shock which would require them to withdraw early, irrespective of $\theta$. This can also be understood as each agent having $\lambda$ probability of being hit by a liquidity shock. There is no aggregate uncertainty (i.e. $\lambda$ is fixed and known), but the bank cannot distinguish the type of each agent individually. The bank keeps a reserve $\rho$ to meet early demand in $t_{1}$. The reserves has to be at least $\lambda r$ to meet the demand of the impatient agents who will definitely withdraw. If $\rho$ turns out to be more than that, it shows inefficiency. To analyse the inefficiency we can say that $\rho=\lambda r+(1-\lambda) \pi$, where $\pi$ indicates the extent of inefficiency in having to keep more reserves over and above what is needed to serve the genuinely impatient agents.

Because the bank operates in a competitive environment, it will choose $r$ and $\rho$ to maximise the expected utility of the depositors subject to zero profit.

\section{Unique Equilibrium}

First we have to establish that a unique equilibrium $\theta^{*}$ exists, below which everyone will withdraw and above which no one will withdraw. In keeping with the literature, one of the conditions that is needed to get this unique equilibrium is that $\theta$ should have an upper dominant region and a lower dominant region. Explaining this further, it should be feasible to get an extremely good signal where the return is so high that no patient agent would want to withdraw early regardless of the behaviour of the other agents. These signals are said to belong to the upper dominant region. There also exists a lower dominant region where you receive an extremely bad signal and the returns are so low that the agent would definitely withdraw even if no other patient agent withdraws. A very small probability of an occurrence of these dominant regions is sufficient (never the less it is needed) to drive a unique equilibrium $\theta^{*}$ so that the patient agent $i$ would not withdraw in $t_{1}$ if and only if $\theta_{i}>\theta^{*}$ and would withdraw regardless of his type if $\theta_{i}<\theta^{*}$.

When only impatient agents withdraw, if an agent does not withdraw he will get a payoff of $\frac{(1-\rho) \theta+\rho-\lambda r}{1-\lambda}$. This value has to be less than or equal to $r$ for it to be worthwhile withdrawing.. If the realisation of $\theta$ was such that when only the impatient $\lambda$ agents withdraw, the return he gets is $\frac{(1-\rho) \theta+(1-\lambda) \pi}{1-\lambda} \leq r$ it is better to withdraw early even if no other patient agent withdraws. For this to be true, the fundamental should be lower than $\underset{\sim}{\theta}\left(\underset{\sim}{\theta}=\frac{(1-\lambda)(r-\pi)}{1-\rho}\right)$. The lower dominant region is $[\underset{\sim}{\theta}, \underset{\sim}{\theta})$ where everyone will 
withdraw. The difference between an agent's signal and the true value of $\theta$ will not be more than $e$ and therefore if player $i$ 's signal is $\theta_{i}<\theta-e$ he will definitely withdraw because he knows that $\theta<\theta$.

Likewise the upper dominant region is $(\widetilde{\theta}, \bar{\theta}]$ where $\theta$ is so high that even if everyone else withdraws it is better for the patient agent not to withdraw. We assume that when $\theta$ is very high, the bank is able to obtain loans against their investments at a very high interest rate $\gamma$. The bank will have to settle the loan before distributing the profit to the depositors who waited. If everyone else withdraws the bank will need a loan of $(r-\rho)$. The bank will be able to get this loan if $(1-\rho) \theta-(r-\rho)(1+\gamma) \geq 0$. When $\theta$ is high enough so that the bank can secure this loan, if the agent withdraws early, he will receive $r$. If he does not withdraw he will receive $(1-\rho) \theta-(r-\rho)(1+\gamma)$. If $(1-\rho) \theta-(r-\rho)(1+\gamma) \geq r$ the agent is better off by not withdrawring even if everyone else withdraws. This gives $\widetilde{\theta}=\frac{r+(r-\rho)(1+\gamma)}{(1-\rho)}$. The agents are aware of this. If the signal that a patient player $i$ receives is $\theta_{i}>\tilde{\theta}+e$ he will definitely not withdraw because he knows that $\theta>\widetilde{\theta}$.

If an agent receives a signal close to a dominant region, there is a probability that there would be some who have received signals within that dominant region and therefore have a dominant strategy. This will ensure that this player also to follow that strategy. This process can be iterated so that we eventually arrive at the unique threshold point where the agent will be indifferent between withdrawing or not withdrawing.

A threshold $\theta^{*}$ can be computed for cases where $\lambda=0$ and $\lambda>0$. When computing $\theta^{*}$ we only consider the range $\left[\theta^{*}-e, \theta^{*}+e\right]$ and assume that the dominant regions are extreme enough that they will not have an influence over $\theta^{*}$.

\subsection{Threshold $\theta^{*}$}

Once $\theta$ is realised player $i$ observes a signal $\theta_{i}=\theta+\varepsilon_{i}$. The strategy in $t_{1}$ for an impatient agent (who is hit by the liquidity shock) is to withdraw irrespective of his signal. The strategy for the patient player is given as the map:

$$
s_{i}:[\theta-e, \widetilde{\theta}+e] \rightarrow\{\text { withdraw, not withdraw }\} .
$$

We consider threshold strategies and set out the conditions for $\theta^{*}$ to be a symmetric equilibrium. 
The threshold strategy for each player would be

$$
\begin{aligned}
s_{i} & =\text { withdraw if } \theta_{i}<\theta_{i}^{*} . \\
& =\text { not withdraw if } \theta_{i}>\theta_{i}^{*} .
\end{aligned}
$$

Symmetric threshold strategy would mean $\theta_{i}^{*}=\theta^{*}$, for every player $i$.

If a patient agent $i$ observes a signal $\theta_{i}>\theta^{*}$, he will not withdraw. This is because he would then believe that the return on the project is going to be high enough and sufficient number of other depositors will also decide the same. If he observes $\theta_{i}<\theta^{*}$, he will withdraw because he believes that sufficiently high enough number of the other agents would have received a signal which would prompt them to withdraw, so that if he waited till the next period he would get nothing.

Proposition 1 There exists a unique equilibrium $\theta^{*}$ such that if agents received a signal below that they would withdraw in $t_{1}$ and if they received a signal above that they would not withdraw in $t_{1}$ unless they are hit by the liquidity shock.

The following discussion leads to the proof of proposition 1: For now, let patient agents withdraw if they receive a signal less than $\widehat{\theta}$. Agent $i$ has received a signal $\theta_{i}$. Player $i$ 's posterior distribution of the $\theta$ that is realised, which we call $y\left(=\theta / \theta_{i}\right)$ is uniform on $\left[\theta_{i}-e, \theta_{i}+e\right]$. ${ }^{4}$

$$
\begin{array}{r}
f(y) \quad=\frac{1}{2 e} \text { if } y \in\left[\theta_{i}-e, \theta_{i}+e\right] . \\
=0 \text { if } y \notin\left[\theta_{i}-e, \theta_{i}+e\right] .
\end{array}
$$

This is true for all except those points very close to the ends. (This would not be true for $\theta<\underset{\sim}{\theta}+e$ and $\theta>\widetilde{\theta}-e$.

For each point $y \in\left[\theta_{i}-e, \theta_{i}+e\right]$, he will believe that all the other agents would have received independent and uniformly distributed signals $[y-e, y+e]$ and hence the proportion of patient agents whom he believes would withdraw (i.e. those who received a signal less than $\widehat{\theta})$ is a distribution $\widetilde{\omega}(y) \in[0,1]$ given by:

$$
\widetilde{\omega}=\left\{\begin{array}{ccr}
0 & \text { if } & y>\widehat{\theta}+e \\
1 & \text { if } & y<\widehat{\theta}-e \\
\frac{\widehat{\theta}-y+e}{2 e} & \text { if } & \widehat{\theta}-e \leq y \leq \widehat{\theta}+e
\end{array}\right\} .
$$

$$
\begin{aligned}
& { }^{4} \text { Let } \widehat{\theta} \in\left[\theta_{i}-e, \theta_{i}+e\right] \\
& \operatorname{Pr}\left(\theta=\widehat{\theta} / \theta_{i}\right)=\frac{\frac{1}{\theta-\underline{\theta}} * \frac{1}{2 e}}{\int_{\theta_{i}-e}^{\theta_{i}-e} \frac{1}{\theta-\underline{\theta}} * \frac{1}{2 e} d \theta^{\prime}}=\frac{1}{2 e}
\end{aligned}
$$


At each point of $y$ his belief about the proportion who withdraw would be

$$
\lambda+\widetilde{\omega}(y) *(1-\lambda) .
$$

When the depositors receive private signals about $\theta$ in $t_{1}$, they will withdraw if their signal was a value less than $\widehat{\theta}$. But if any player observes a value more than $\widehat{\theta}$ he will withdraw only if he was impatient. Proportion $\lambda$ of the agents would turn out to be impatient and withdraw early because of the liquidity shock irrespective of $\theta$. Proportion $\widetilde{\omega}$ out of the $(1-\lambda)$ patient agents would be believed to withdraw because of the bad signal they received.

The bank keeps a reserve $\rho(=\lambda r+\pi(1-\lambda))$. The amount $\lambda r$ is to cater for the demand by the impatient agents who will definitely withdraw. In addition to that, $\pi(1-\lambda)$ is kept as reserves for the patient agents who might want to withdraw early in $t_{1}$. Therefore it is rational that $\rho \in(\lambda r, r)$. Note that this is over and above the reserves in the first-best case. If demand for withdrawals exceed the liquidity available, the bank would crash because the assets are liquidated for a very small amount.

Let player $i$ receive signal $\theta_{i}$. Expected returns to the agent $i$ who receives signal $\theta_{i}$ if he runs is as follows:

1) If $\lambda r+(1-\lambda) \widetilde{\omega} r<\rho \Leftrightarrow y>\widehat{\theta}+e-\frac{2 e \pi}{r}:$ he believes there is sufficient reserves to meet the demand and therefore will receive $r$ for sure, giving him an expected utility of,

$$
\int_{\widehat{\theta}+e-\frac{2 e \pi}{r}}^{\theta_{i}+e} \frac{1}{2 e} u(r) d y
$$

2) If $\lambda r+(1-\lambda) \widetilde{\omega} r>\rho \Leftrightarrow y<\widehat{\theta}+e-\frac{2 e \pi}{r}:$ he believes there isn't sufficient reserves to meet the demand. Therefore he receives $r$ with probability $\frac{\rho}{\lambda r+(1-\lambda) \widetilde{\omega} r}$ giving an expected utility of,

$$
\int_{\theta_{i}-e}^{\widehat{\theta}+e-\frac{2 e \pi}{r}} \frac{1}{2 e} * \frac{\rho}{\lambda r+(1-\lambda) \widetilde{\omega}(y) r} u(r) d y .
$$

On the other hand, if the agent $i$ does not run, he believes that he will not get anything if $\lambda r+(1-\lambda) \widetilde{\omega} r>\rho$ because the bank would have crashed in $t_{1}$ itself. However, if $\lambda r+(1-\lambda) \widetilde{\omega} r<\rho$, he will expect to receive $\frac{\rho-\lambda r-(1-\lambda) * \omega(y) * r+(1-\rho) y}{(1-\lambda)(1-\widetilde{\omega}(y))}$ in $t_{2}$. This gives him an expected utility of: 


$$
\int_{\widehat{\theta}+e-\frac{2 e \pi}{r}}^{\theta_{i}+e} \frac{1}{2 e} * u\left(\frac{\rho-\lambda r-(1-\lambda) * \widetilde{\omega}(y) * r+(1-\rho) y}{(1-\lambda)(1-\widetilde{\omega}(y))}\right) d y .
$$

The returns that agent $i$ (who is patient) would get can be summarised as follows:

\begin{tabular}{|l|l|l|}
\hline & $\lambda r+(1-\lambda) \widetilde{\omega} r \leq \rho$ & $\lambda r+(1-\lambda) \widetilde{\omega} r>\rho$ \\
\hline Withdraw early & $r$ & $r$ with probability $\frac{\rho}{\lambda r+(1-\lambda) \widetilde{\omega} r}$ \\
\hline Not withdraw early & $\frac{\rho-\lambda r-(1-\lambda) * \widetilde{\omega} * r+(1-\rho) y}{(1-\lambda)(1-\widetilde{\omega})}$ & 0 \\
\hline
\end{tabular}

The difference in the expected utility of agent $i$ who received signal $\theta_{i}$ between withdrawing and not withdrawing is given by:

$$
\begin{aligned}
& g\left(\theta_{i}, \widehat{\theta}\right)=E U\left(\text { withdraw/ } \theta_{i}\right)-E U\left(\text { not withdraw/ } \theta_{i}\right) \\
& g\left(\theta_{i}(r, \pi, \lambda)\right)= \int_{\theta_{i}-e}^{\widehat{\theta}+e-\frac{2 e \pi}{r}} \frac{1}{2 e} * \frac{\rho}{\lambda r+(1-\lambda) \widetilde{\omega}(y) r} u(r) d y+ \\
&+\int_{\widehat{\theta}+e-\frac{2 e \pi}{r}}^{\theta_{i}+e} \frac{1}{2 e} u(r) d y+ \\
&-\int_{\widehat{\theta}+e-\frac{2 e \pi}{r}}^{\theta_{i}+e} \frac{1}{2 e} * u\left(\frac{\rho-\lambda r-(1-\lambda) * \widetilde{\omega}(y) * r+(1-\rho) y}{(1-\lambda)(1-\widetilde{\omega}(y))}\right) d y .
\end{aligned}
$$

The proof that there exists a unique point $\theta_{i}=\theta^{*}$ such that $g\left(\theta^{*}(r, \pi, \lambda)\right)=0$ where player $i$ is indifferent between withdrawing and not, is found in appendix 1 . Since all agents are identical, all patient players would withdraw if the received a signal below $\theta^{*}$, and will not withdraw if they received a signal $\theta^{*}$.

\subsection{Comparative Statics on $\theta^{*}$}

Having higher $r$ provides incentive for the agents to withdraw early. So, if we want to minimise the probability of bank runs (i.e. minimise $\theta^{*}$ ), we should penalise all those who withdraw early including those who are genuinely hit by the liquidity shock. Furthermore, depositors realise that more the early return, $r$, more the probability that the reserves might not be sufficient to meet early demand.

On the other hand when $\pi$ increases, the agents will have more confidence that the bank will survive till $t_{2}$ and will be willing to wait. Therefore $\theta^{*}$ will go down with $\pi$.

It is also intuitive that the threshold $\theta^{*}$ increases with the proportion of impatient investors, $\lambda$. Higher the probability of liquidity shock, higher the probability that 
patient investors will also withdraw early. This is because higher reserves need to be kept, reducing the long-term return. When the probability of getting hit by a liquidity shock is higher, the depositors want higher insurance in the form of a higher $r$. All these factors encourage the patient agents also to withdraw early. These results are summarised in proposition 2 .

Proposition 2 The threshold $\theta^{*}$ increases with $r$ and $\lambda$, but decreases with $\pi$.

Proof. Using equation 1 that gives the difference in expected utility when running and not running so that the indifferent condition for the agent to withdraw early or wait is when $g\left(\theta^{*}(r, \pi, \lambda)\right)=0$.

$$
\begin{aligned}
g\left(\theta^{*}(r, \pi, \lambda)\right)= & \int_{\theta^{*}-e}^{\theta^{*}+e-\frac{2 e \pi}{r}} \frac{1}{2 e} * \frac{\rho(\lambda, r, \pi)}{\lambda r+(1-\lambda) \widetilde{\omega}(y) r} u(r) d y+\int_{\theta^{*}+e-\frac{2 e \pi}{r}}^{\theta^{*}+e} \frac{1}{2 e} u(r) d y \\
& -\int_{\theta^{*}+e-\frac{2 e \pi}{r}}^{\theta^{*}+e} \frac{1}{2 e} * u\left(\frac{(1-\lambda)(\pi-\widetilde{\omega}(y)) r+(1-\rho) y}{(1-\lambda)(1-\widetilde{\omega}(y))}\right) d y .
\end{aligned}
$$

As $\theta^{*}$ increases, more people withdraw early. For given reserves, $\rho$ and early return, $r$ the expected return by withdrawing early is therefore less. This means the first two terms go down with $\theta^{*}$. The expected return by withdrawing late increases.

$$
\frac{\partial g}{\partial \theta^{*}}=\frac{1}{2 e}\left(\begin{array}{c}
-\left(\frac{(1-\lambda) \pi}{\lambda r}\right) u(r)-\rho u(r)(1-\lambda) \int_{\theta^{*}-e}^{\theta^{*}+e-\frac{2 e \pi}{r}} \frac{d y}{(\lambda r+(1-\lambda) \widetilde{\omega} r)^{2}} \\
-\int_{\theta^{*}+e-\frac{2 e \pi}{r}}^{\theta^{*}+e}\left(\frac{u^{\prime}(.)}{2 e(1-\lambda)(1-\widetilde{\omega})^{2}}((1-\rho) y-(1-\lambda)(1-\pi) r)\right) d y
\end{array}\right)<0
$$

Consider what happens to $g$ when $r$ is increased. If you withdraw early, you are better off if $r$ is high. The first two terms in equation (2) increase with $r$. The return to those who do not withdraw, given by the third term however, goes down with $r$. Therefore $\frac{\partial g}{\partial r}>0$. By the implicit function theorem $\frac{d \theta^{*}}{d r}>0$. So, $\theta^{*}$ increases with $r$. Q.E.D.

What happens to $\theta^{*}$ when $\lambda$ changes? The second term in $g$ is not affected by $\lambda$. In the first term, because $\frac{\pi}{r}<\widetilde{\omega}<1$, an increase in $\lambda$ will reduce the denominator more than the numerator. Hence, the whole term will go up with $\lambda$. This is because, when there are more impatient agents, it pays to withdraw early. The last term relates to the returns you get by not withdrawing. More the $\lambda$, less the return for those who 
wait. Therefore $\frac{\partial g}{\partial \lambda}>0$. We know that $\frac{\partial g}{\partial \theta^{*}}<0$. Therefore $\frac{d \theta^{*}}{d \lambda}>0$. So, $\theta^{*}$ increases with $\lambda$.

Q.E.D.

Finally we look at what happens to $\theta^{*}$ when $\pi$ changes.

$$
\begin{aligned}
\frac{\partial g}{\partial \pi}= & -\frac{1}{r} u\left(\frac{(1-\rho)\left(\theta^{*}+e-\frac{2 e \pi}{r}\right)}{(1-\lambda)\left(1-\frac{\pi}{r}\right)}\right) \\
& +\int_{\theta^{*}-e}^{\theta^{*}+e-\frac{2 e \pi}{r}} \frac{1}{2 e} \frac{(1-\lambda) u(r)}{\lambda r+(1-\lambda) \widetilde{\omega}(y) r} d y \\
& -\int_{\theta^{*}+e-\frac{2 e \pi}{r}}^{\theta^{*}+e} \frac{1}{2 e} u\left(\frac{1-y}{1-\widetilde{\omega}}\right) d y . \\
\left.\frac{\partial g}{\partial \pi}\right|_{\pi=0}=-\frac{1}{r} u & \left(\frac{(1-\lambda r)\left(\left.\theta^{*}\right|_{\pi=0}+e\right)}{(1-\lambda)}\right)-\frac{u(r)}{r} \log (\lambda)<0 .
\end{aligned}
$$

Note that

$$
\left.g\left(\theta^{*}\right)\right|_{\pi \rightarrow 0}=\int_{\theta^{*}-e}^{\theta^{*}+e} \frac{1}{2 e} * \frac{\lambda r}{\lambda r+(1-\lambda) \frac{\theta^{*}+y-e}{2 e} r} u(r) d y,
$$

Therefore $\left.\theta^{*}\right|_{\pi=0}$ is very large, close to the upper dominant region. So we can say that $\left.\frac{\partial g}{\partial \pi}\right|_{\pi=0}<0$.

$$
\begin{gathered}
\left.\frac{\partial g}{\partial \pi}\right|_{\pi \rightarrow r} \rightarrow-\infty<0 . \\
\frac{d^{2} g}{d \pi^{2}}=-\frac{1}{r}\left(\begin{array}{c}
\frac{u^{\prime}(.)(1-\rho)\left(\theta^{*}-e\right)}{r\left(1-\frac{\pi}{r}\right)^{2}}+ \\
+\frac{(1-\lambda) u(r)}{\lambda r+(1-\lambda) \pi}+u\left(\frac{1-\theta^{*}-e+\frac{2 e \pi}{r}}{1-\frac{\pi}{r}}\right)
\end{array}\right)<0 .
\end{gathered}
$$

Therefore we can conclude that $\frac{\partial g}{\partial \pi}<0$. We know that $\frac{\partial g}{\partial \theta^{*}}<0$, which means $\frac{d \theta^{*}}{d \pi}<0$. So, $\theta^{*}$ deccreases with $\pi$.

\section{Maximising Expected Utility}

\subsection{First Best}

As the benchmark, we look at the first-best scenario where the bank not only knows that $\lambda$ proportion of the depositors will be affected by liquidity shocks, but also knows 
exactly who is impatient and who is patient. Therefore, the bank will be able to offer a contract which promises return $r$ in $t_{1}$ only to those $\lambda$ proportion of agents who are impatient. Patient agents will not be served in $t_{1}$. The bank will therefore keep reserves $\rho=\lambda r$ which is just sufficient to meet the demand from the impatient agents. The patient agents will have to wait till $t_{2}$ and receive $\frac{(1-\rho) \theta}{1-\lambda}\left(=\frac{(1-\lambda r) \theta}{1-\lambda}\right)$.

In this case, there will be no bank run because the patient agents will not receive anything early. The threshold $\theta^{*}$ turns out to be equal to $\underline{\theta}$. Therefore the expected utility of an agent is:

$$
E U_{F B}=\lambda u(r)+(1-\lambda) \int_{\underline{\theta}}^{\bar{\theta}} \frac{1}{\bar{\theta}-\underline{\theta}} u\left(\frac{(1-\lambda r) \theta}{(1-\lambda)}\right) d \theta .
$$

The first-order condition for optimal early return $r_{F B}^{*}$,

$$
\begin{gathered}
\frac{d E U_{F B}}{d r}=\lambda u^{\prime}(r)+\frac{(1-\lambda)}{\bar{\theta}-\underline{\theta}} \int_{\underline{\theta}}^{\bar{\theta}} u^{\prime}\left(\frac{(1-\lambda r) \theta}{1-\lambda}\right)\left(\frac{-\lambda \theta}{1-\lambda}\right) d \theta=0 . \\
\frac{d^{2} E U_{F B}}{d r^{2}}=\lambda u^{\prime \prime}(r)+\frac{\lambda^{2}}{(1-\lambda)(\bar{\theta}-\underline{\theta})} \int_{\underline{\theta}}^{\bar{\theta}}\left(u^{\prime \prime}\left(\frac{(1-\lambda r) \theta}{(1-\lambda)}\right) \theta^{2} d \theta\right) .
\end{gathered}
$$

Since $u^{\prime \prime}()<0,. \frac{d^{2} E U_{F B}}{d r^{2}}<0$

We use the benchmark result to compare with the results when the bank cannot distinguish between the two types. In bank run models agents can also withdraw early because of self fulfilling beliefs, and therefore banks face the risk of unnecessary failure. What is important in this exercise is to find the optimal level of reserves and early return rates that will maximise the expected utility of the investors, taking into consideration the possibility of too much early withdrawal and bankruptcy.

\subsection{Expected Utility}

The bank operates in a competitive environment and therefore wants to maximise the expected utility of the agent subject to zero profit. When $\underline{\theta}<\theta<\theta^{*}-e$ there is total run because everyone would receive a signal that is below the threshold value. When $\theta^{*}+e<\theta<\bar{\theta}$ no one will withdraw early because all the players would receive signals that are above $\theta^{*}$. But when $\theta^{*}-e<\theta<\theta^{*}+e$ we have a partial run. The probability of partial run is close to zero because noise is very small and can be ignored. 
Therefore, if $\theta<\theta^{*}$ everybody will withdraw early, whose demand has to be met with the available reserves $\rho$. On the other hand, if $\theta>\theta^{*}$, only those who are impatient will withdraw early. In which case, the player has $\lambda$ probability of being impatient and receives $r$, and he has $(1-\lambda)$ probability of being patient and receives $\left(\frac{\rho-\lambda r+(1-\rho) \theta}{1-\lambda}\right)$.

Therefore the expected utility of each agent at the beginning of $t_{0}$ can be written as follows:

$$
\begin{aligned}
E U= & \int_{\underline{\theta}}^{\theta^{*}} \frac{1}{\bar{\theta}-\underline{\theta}} \frac{\rho}{r} u(r) d \theta+ \\
& +\int_{\theta^{*}}^{\bar{\theta}} \frac{1}{\bar{\theta}-\underline{\theta}}\left[\lambda u(r)+(1-\lambda) u\left(\frac{\rho-\lambda r+(1-\rho) \theta}{1-\lambda}\right)\right] d \theta .
\end{aligned}
$$

The optimal reserve level and early return will be decided by maximising $E U$ given by equation (11).

\subsection{Reserves}

Recall that the reserves is given by $\rho=\lambda r+\pi(1-\lambda)$. The amount $\pi(1-\lambda)$ is put aside to cater to the demand of patient agents who might withdraw early because of self fulfilling beliefs. If $\pi^{*}>0$, the optimal level of reserves $\rho^{*}>\lambda r$. This means the bank is keeping as reserves more than what is needed to meet the demand of those who are genuinely hit by the liquidity shock. Keeping excess reserves reduces the amount that can be invested in profitable projects. Higher the $\pi$, higher this inefficiency.

Proposition 3 When $\lambda>0, \pi^{*}>0$ which shows there is inefficiency in the optimal level of reserves.

Proof. The first-order condition to choose optimal $\pi^{*}$ is $\frac{\partial E U}{\partial \pi}=0$.

$$
\frac{\partial E U}{\partial \pi}=\frac{1}{\bar{\theta}-\underline{\theta}} *\left(\begin{array}{c}
\frac{\lambda r+(1-\lambda) \pi^{*}}{r} u(r) \frac{d \theta^{*}}{d \pi}+\int_{\underline{\theta}}^{\theta^{*}} \frac{(1-\lambda)}{r} u(r) d \theta+ \\
-\left[\lambda u(r)+(1-\lambda) u\left(\frac{(1-\lambda) \pi^{*}+\left(1-\lambda r-\pi^{*}(1-\lambda)\right) \theta^{*}}{1-\lambda}\right)\right] \frac{d \theta^{*}}{d \pi}+ \\
+\int_{\theta^{*}}^{\bar{\theta}}\left[(1-\lambda) u^{\prime}\left(\frac{(1-\lambda) \pi^{*}+\left(1-\lambda r-\pi^{*}(1-\lambda)\right) \theta}{1-\lambda}\right)(1-\theta)\right] d \theta
\end{array}\right)=0 .
$$


When $\pi=0$;

$$
\left.\frac{\partial E U}{\partial \pi}\right|_{\pi=0}=\frac{1-\lambda}{\bar{\theta}-\underline{\theta}} *\left(\begin{array}{c}
-\left.u\left(\frac{\left.(1-\lambda r) \theta^{*}\right|_{\pi=0}}{1-\lambda}\right) * \frac{d \theta^{*}}{d \pi}\right|_{\pi=0}+\frac{\left.u(r) \theta^{*}\right|_{\pi=0}}{r}+ \\
+\int_{\left.\theta^{*}\right|_{\pi=0}}^{\bar{\theta}} u^{\prime}\left(\frac{(1-\lambda r) \theta}{1-\lambda}\right)(1-\theta) d \theta
\end{array}\right) .
$$

Since $\left.\frac{\partial \theta^{*}}{\partial \pi}\right|_{\pi=0}<0$ and $\left.\theta^{*}\right|_{\pi=0}$ is large, it is obvious that $\left.\frac{\partial E U}{\partial \pi}\right|_{\pi=0}>0$. This shows that the optimal reserve is such that $\pi^{*}>0$.

The next proposition says that the inefficiency of keeping excess reserves, captured by $\pi$, increases with the proportion of impatient agents $\lambda$ and reduces with the earning capacity of the bank $\bar{\theta}$. The inefficiency of keeping excess reserves is caused by the existence of impatient agents. Higher the $\lambda$, more the reserves that should be put aside. This not only reduces the opportunity of cost of withdrawing early to the patient agents but also increases their risk if they do not withdraw early. Therefore higher the $\lambda$ higher the probability that patient agents will panic and withdraw early and hence higher reserves should be put aside to meet their early demand.

Though the inefficiency of excess reserves increases with $\lambda$, it decreases with the earning capacity of the long term project. To capture the earning capacity, we look at what happens when $\bar{\theta}$ increases. It is quite intuitive that when the expected return from waiting is more, those who are patient are less tempted to withdraw early and therefore reduce the need for excess reserves.

Proposition 4 The inefficiency in reserves given by $\pi^{*}$ increases with $\lambda$ and decreases with $\bar{\theta}$.

Proof. We use the first-order condition for $\pi^{*}$ given by equation (12). Let

$$
\begin{aligned}
h\left(\pi^{*}(\lambda, \bar{\theta})\right)= & \frac{\partial E U}{\partial \pi} . \\
h\left(\pi^{*}(\lambda, \bar{\theta})\right)= & \frac{\lambda r+(1-\lambda) \pi^{*}}{r} u(r) \frac{d \theta^{*}}{d \pi}+\int_{\underline{\theta}}^{\theta^{*}} \frac{(1-\lambda)}{r} u(r) d \theta \\
& -\left(\lambda u(r)+(1-\lambda) u\left(\frac{(1-\lambda) \pi^{*}+\left(1-\lambda r-\pi^{*}(1-\lambda)\right) \theta^{*}}{1-\lambda}\right)\right) \frac{d \theta^{*}}{d \pi} \\
& +\int_{\theta^{*}}^{\bar{\theta}}\left((1-\lambda) u^{\prime}\left(\frac{(1-\lambda) \pi^{*}+\left(1-\lambda r-\pi^{*}(1-\lambda)\right) \theta}{1-\lambda}\right)(1-\theta)\right) d \theta .
\end{aligned}
$$

Because $h=\frac{\partial E U}{\partial \pi}$ and we are maximising $E U, \frac{\partial h}{\partial \pi^{*}}<0$. Moreover, we know that 
$E U$ goes down with $\lambda$ : $\frac{\partial E U}{\partial \lambda}<0$. The reduction in $E U$ when $\pi$ increases, also increases when $\lambda$ increases. This means, $\frac{\partial h}{\partial \lambda}>0$ and therefore $\frac{d \pi^{*}}{d \lambda}>0$. So, $\pi^{*}$ increases with $\lambda$. Q.E.D.

We know that $\frac{\partial h}{\partial \pi^{*}}<0$. Moreover, we know that $E U$ increases with $\bar{\theta}: \frac{\partial E U}{\partial \bar{\theta}}>0$. Therefore the reduction in $E U$ when $\pi$ increases, decreases when $\bar{\theta}$ also increases. Therefore $\frac{\partial h}{\partial \bar{\theta}}<0$ which means, $\frac{d \pi^{*}}{d \bar{\theta}}<0$. So, $\pi^{*}$ deccreases with $\bar{\theta}$.

\subsection{Early Return}

Next we look at some results about the optimal early return $r^{*}$. Higher the probability that agents could be impatient, the more they would like to receive as early return. Further more, when $\lambda$ is high, the patient depositors would like to withdraw early because they know that more people will be withdrawing early, depleting the reserves. Both these reasons combined result in the $r^{*}$ increasing with $\lambda$. On the other hand, when $\bar{\theta}$ is higher, the expected utility of waiting is higher, which pushes down the required $r^{*}$.

Proposition 5 The optimal level of early returns $r^{*}$ increases with $\lambda$ and decreases with $\bar{\theta}$.

Proof. We use the first-order condition for choosing optimal $r, \varphi\left(r^{*}(\lambda, \bar{\theta})\right)=$ $\frac{\partial E U}{\partial r}=0$,

$$
\begin{aligned}
\varphi\left(r^{*}(\lambda, \bar{\theta})\right)= & \frac{\lambda r^{*}+(1-\lambda) \pi}{r^{*}} u\left(r^{*}\right) \frac{d \theta^{*}}{d r} \\
& +\int_{\underline{\theta}}^{\theta^{*}} \lambda u^{\prime}\left(r^{*}\right)+\frac{(1-\lambda) \pi}{r^{* 2}}\left(r^{*} u^{\prime}\left(r^{*}\right)-u\left(r^{*}\right)\right) d \theta \\
& -\left(\lambda u\left(r^{*}\right)+(1-\lambda) u\left(\frac{(1-\lambda) \pi+\left(1-\lambda r^{*}-\pi(1-\lambda)\right) \theta^{*}}{1-\lambda}\right)\right) \frac{d \theta^{*}}{d r} \\
& +\int_{\theta^{*}}^{\bar{\theta}}\left((1-\lambda) u^{\prime}\left(\frac{(1-\lambda) \pi+\left(1-\lambda r^{*}-\pi(1-\lambda)\right) \theta}{1-\lambda}\right)\left(\frac{-\lambda \theta}{1-\lambda}\right)\right) d \theta
\end{aligned}
$$

Because $u(r)$ is concave, the first term in the $E U$ function (i.e. the expected utility when the depositor will have to withdraw because his signal is below the threshold level) is also concave. In the second part, $\lambda u(r)$ as well as $(1-\lambda) u\left(\frac{(1-\lambda) \pi+(1-\lambda r-\pi(1-\lambda)) \theta}{1-\lambda}\right)$ 
are concave. Thereby, the whole expression of $E U$ is concave and therefore $\frac{\partial^{2} E U}{\partial r^{2}}<0$. This means $\frac{\partial \varphi}{\partial r^{*}}<0$.

Moreover, we know that $E U$ goes down with $\lambda$ : $\frac{\partial E U}{\partial \lambda}<0$. The reduction in $E U$ when $r$ increases, also increases when $\lambda$ increases. This means, $\frac{\partial \varphi}{\partial \lambda}>0$ and therefore $\frac{d r^{*}}{d \lambda}>0$.

So, $r^{*}$ increases with $\lambda$.

Q.E.D

Next we see how $r^{*}$ behaves with $\bar{\theta}$.

$$
\frac{\partial \varphi}{\partial \bar{\theta}}=\lambda u^{\prime}\left(r^{*}\right)+(1-\lambda) u^{\prime}\left(\frac{(1-\lambda) \pi+\left(1-\lambda r^{*}-\pi(1-\lambda)\right) \theta}{1-\lambda}\right)\left(\frac{-\lambda \bar{\theta}}{1-\lambda}\right) .
$$

Because $\bar{\theta}$ is large, $\frac{\partial \varphi}{\partial \bar{\theta}}<0$. Moreover, we know that $E U$ increases with $\bar{\theta}: \frac{\partial E U}{\partial \bar{\theta}}>0$. Therefore the reduction in $E U$ when $r$ increases, decreases when $\bar{\theta}$ also increases which means $\frac{\partial \varphi}{\partial \bar{\theta}}<0$. We already know that $\frac{\partial \varphi}{\partial r^{*}}<0$. Therefore, $\frac{d r^{*}}{d \bar{\theta}}<0$. So, $r^{*}$ deccreases with $\bar{\theta}$.

Proposition 6 below gives an interesting result.

Proposition 6 When there are impatient agents, the optimal level of early returns $0<r^{*}<1$.

Proof. Recall the first order condition for choosing optimal $r$ given by equation $(15)$,

$$
\left.\frac{\partial E U}{\partial r}\right|_{r=0}=(1-\lambda)\left(\begin{array}{c}
\frac{\pi}{r^{2-\alpha}}+u\left(\pi+\frac{(1-\pi(1-\lambda)) \theta^{*}}{1-\lambda}\right) \frac{d \theta^{*}}{d r}+ \\
-\int_{\theta^{*}}^{\bar{\theta}}\left(u^{\prime}\left(\frac{(1-\lambda) \pi+(1-\pi(1-\lambda)) \theta}{1-\lambda}\right)\left(\frac{\lambda \theta}{1-\lambda}\right)\right) d \theta
\end{array}\right) .
$$

Since the first term goes to $+\infty,\left.\frac{\partial E U}{\partial r}\right|_{r=0}>0$.

$$
\left.\frac{\partial E U}{\partial r}\right|_{r=1}=\frac{1}{\bar{\theta}-\underline{\theta}} *\left(\begin{array}{c}
\lambda+(1-\lambda) \pi \frac{d \theta^{*}}{d r} \\
+\int_{\underline{\theta}}^{\theta^{*}} \lambda \alpha+(1-\lambda) \pi(\alpha-1) d \theta+ \\
-\left(\lambda+(1-\lambda) u\left(\frac{(1-\lambda) \pi+(1-\lambda-\pi(1-\lambda)) \theta}{1-\lambda}\right)\right) \frac{d \theta^{*}}{d r}+ \\
+\left(\int_{\theta^{*}}^{\bar{\theta}} \lambda \alpha+(1-\lambda) u^{\prime}\left(\frac{(1-\lambda) \pi+(1-\lambda-\pi(1-\lambda)) \theta}{1-\lambda}\right)\left(\frac{-\lambda \theta}{1-\lambda}\right)\right) d \theta
\end{array}\right) .
$$

We can re-write the above as follows: 


$$
\left.\frac{\partial E U}{\partial r}\right|_{r=1}=\frac{1}{\bar{\theta}-\underline{\theta}} *\left(\begin{array}{c}
-(1-\lambda) \pi(1-\alpha) \theta^{*} \\
-(1-\lambda)\left[u\left(\pi+(1-\pi) \theta^{*}\right)-\pi\right] \frac{d \theta^{*}}{d r} \\
-\int_{\theta^{*}}^{\bar{\theta}} u^{\prime}\left(\frac{(1-\lambda) \pi+(1-\lambda-\pi(1-\lambda)) \theta}{1-\lambda}\right) \lambda \theta d \theta+\lambda \alpha \bar{\theta}
\end{array}\right) .
$$

It is obvious that $\left.\frac{\partial E U}{\partial r}\right|_{r=1}<0$. We know that $\frac{\partial^{2} E U}{\partial r^{2}}<0$ and $r^{*}>0$. Therefore we can conclude that $0<r^{*}<1$.

When there is a probability of being hit by a liquidity shock, high early return, $r$ gives an insurance to the depositors. However, if a high $r$ is offered, it will be an incentive for those who are not hit by the liquidity shock also to withdraw early. This is shown in proposition 2. In order to discourage them from doing so, even those who are genuinely hit by the liquidity shock have to be penalised. This means that the optimal choice of $r$ does not give much in terms of insurance against the liquidity shock. In fact, to maximise expected returns, early return should be less than the investment. Institutional restraints compelling banks to give early returns $r \geq 1$ is a way of ensuring better insurance. However, this has the repercussion of increasing the probability of bank runs.

We go on to show that not only is the early return less than 1 , it is also less than the first best.

Proposition 7 The first-best early return $r_{F B}^{*}$ is higher than the optimal early return $r^{*}$.

Proof. We compare the first order conditions for $r_{F B}^{*}$ and $r^{*}$. The first-order condition for $r^{*}$ given by equation (15) can be rearranged as follows:

$$
\begin{aligned}
& u^{\prime}(r)-\frac{1}{\left(\bar{\theta}-\theta^{*}\right)} \int_{\theta^{*}}^{\bar{\theta}} \theta u^{\prime}\left(\frac{(1-\lambda r) \theta}{1-\lambda}+\pi(1-\theta)\right) d \theta \\
= & \frac{(1-\lambda)\left[u\left(\frac{(1-\lambda) \pi+(1-\lambda r-\pi(1-\lambda)) \theta^{*}}{1-\lambda}\right)-\frac{\pi}{r} u(r)\right] \frac{d \theta^{*}}{d r}-\int_{\underline{\theta}}^{\theta^{*}} \rho\left(\frac{r u^{\prime}(r)-u(r)}{r^{2}}\right) d \theta}{\lambda\left(\bar{\theta}-\theta^{*}\right)} .
\end{aligned}
$$

$u\left(\frac{(1-\lambda) \pi+(1-\lambda r-\pi(1-\lambda)) \theta^{*}}{1-\lambda}\right)>\frac{\pi}{r} u(r)$. i.e. utility when no patient agent withdraws is more than the utility when everyone withdraws. We know that $\frac{d \theta^{*}}{d r}>0$. We also know that $\rho\left(\frac{r u^{\prime}(r)-u(r)}{r^{2}}\right)<0$. This means that the RHS is positive. 
Therefore the LHS is also positive:

$$
u^{\prime}\left(r^{*}\right)-\frac{1}{\left(\bar{\theta}-\theta^{*}\right)} \int_{\theta^{*}}^{\bar{\theta}} \theta u^{\prime}\left(\frac{\left(1-\lambda r^{*}\right) \theta}{1-\lambda}+\pi(1-\theta)\right) d \theta>0 .
$$

However the first order condition for $r_{F B}^{*}$ given by equation (9) says that,

$$
u^{\prime}\left(r_{F B}^{*}\right)-\frac{1}{\bar{\theta}-\underline{\theta}} \int_{\underline{\theta}}^{\bar{\theta}} \theta u^{\prime}\left(\frac{\left(1-\lambda r_{F B}^{*}\right) \theta}{1-\lambda}\right) d \theta=0 .
$$

In the first-best, no unnecessary reserves are kept and therefore more can be invested long term. This means,

$$
\int_{\theta^{*}}^{\bar{\theta}} \theta u^{\prime}\left(\frac{\left(1-\lambda r^{*}\right) \theta}{1-\lambda}-\pi(\theta-1)\right) d \theta>\int_{\underline{\theta}}^{\bar{\theta}} \theta u^{\prime}\left(\frac{\left(1-\lambda r_{F B}\right) \theta}{1-\lambda}\right) d \theta .
$$

- Therefore it must be that $u^{\prime}\left(r^{*}\right)>u^{\prime}\left(r_{F B}\right)$ which leads to the conclusion that $r^{*}<r_{F B}^{*}$.

Proposition 7 above gives a similar result as shown in the Goldstein and Pauzner model. The optimal early return $r^{*}$ turn out to be less than what was computed under the first-best scenario. This is because in the first-best, the bank can observe whether the withdrawer is truly hit by the liquidity shock. Therefore it keeps reserves only to serve the impatient depositors and does not have to use the early return $r$ as an instrument to dissuade patient agents from withdrawing early. When the bank cannot distinguish between the two types, it needs to cater to a higher proportion of withdrawers, and therefore does not want to give them too much early return. With higher $r$, the agents benefit because of higher risk sharing. However, this increases the reserves that are needed and reduces the long-term earning potential and increases the probability of bank runs because it provides incentive for early withdrawal.

\section{Scenario II - Non Transparent Reserve Policy}

\section{$5 \quad$ The Model}

The previous scenario concluded that there is no need for regulation on the level of reserves that a bank should keep because the banks in a competitive environment would choose reserves and early returns to maximise expected utility of the agents. 
The results were driven by the fact that the reserves kept by the bank was public knowledge.

The model is similar to the one in the original one except that now the level of reserves, $\rho(=\lambda r+(1-\lambda) \pi)$, the bank puts aside cannot be observed, which gives rise to moral hazard. Hence, the bank will choose reserves to maximise its profit. Those who wait till the last period receive a proportion of the profit.

Like before, proportion $\omega$ of the agents would receive signals that are low enough that they withdraw early, in addition to the $\lambda$ proportion who would definitely withdraw.

In period $t_{2}$, proportion $\delta$ of the profits is distributed equally among the agents who did not withdraw early. This is different to what happened in the basic model where all the remaining returns were distributed to the agents and the objective was to maximise the expected utility of the agents. Since the reserves cannot be observed in this model, the objective function of the bank is to choose reserves, $\rho$ to maximise its expected profit, $E \Delta$.

For any $\theta$, the profit $\Delta$ for the bank is given as follows:

$$
\Delta=\rho-\lambda r-(1-\lambda) \omega r+(1-\rho) \theta-\frac{(1-\lambda)(1-\omega)}{(1-\lambda)(1-\omega)} \delta \Delta .
$$

Rearranging equation (22),

$$
\Delta=\frac{(1-\rho) \theta+(1-\lambda)(\pi-\omega r)}{(1+\delta)} .
$$

To facilitate the unique equilibrium, we assume that $\theta$ has upper and lower dominant regions. If only the agents who are hit by the liquidity shock withdraw, an agent is better off by withdrawing early if $r \geq \delta \frac{(1-\rho) \theta+(1-\lambda) \pi}{(1+\delta)}$. For this to be true, the fundamental should be lower than $\left.\underset{\sim}{\theta} \underset{\sim}{\theta}=\frac{(1+\delta) r-\delta(1-\lambda) \pi}{\delta(1-\rho)}\right)$. The lower dominant region is $[\underline{\theta}, \theta)$ where everyone will withdraw and therefore if player $i$ 's signal is $\theta_{i}<\theta-e$ he will definitely withdraw because he knows that $\theta<\theta$.

Like before we assume that when $\theta$ is very high, the bank can get a loan at a very high interest rate $\gamma$ to meet early demand. If everyone else withdraws the bank will need a loan of $(r-\rho)$. The bank will be able to get this loan if $(1-\rho) \theta-$ $(r-\rho)(1+\gamma) \geq 0$. When $\theta$ is sufficiently high so that the bank can secure this loan, if the agent withdraws early, he will receive $r$. If he does not withdraw he will receive $\delta \frac{(1-\rho) \theta-(r-\rho)(1+\gamma)}{(1+\delta)}$. As long as $\delta \frac{(1-\rho) \theta-(r-\rho)(1+\gamma)}{(1+\delta)} \geq r$ the agent is better off by not 
withdrawing even if everyone else withdraws. This gives $\widetilde{\theta}=\frac{r(1+\delta)+\delta(r-\rho)(1+\gamma)}{\delta(1-\rho)}$. If the signal that a patient player $i$ receives is $\theta_{i}>\widetilde{\theta}+e$ he will definitely not withdraw because he knows that $\theta>\widetilde{\theta}$. The upper dominant region is $[\underset{\sim}{\theta}, \bar{\theta})$ where no patient agent will withdraw.

\section{Threshold $\theta^{*}$}

As in the basic model, we consider threshold strategies and set out the conditions for $\theta^{*}$ to be a symmetric equilibrium. If a patient player observes $\theta_{i}>\theta^{*}$ he will not withdraw and he will will withdraw if $\theta_{i}<\theta^{*}$.

Note that even though reserves, $\rho$, is not observable, the agents will predict it in equilibrium, and choose $\theta^{*}$ accordingly. If the reserves is sufficient to meet early demand, withdrawers in $t_{1}$ receive $r$ and the bank makes $\Delta$ profit. Those agents who wait till $t_{2}$ receive $\delta \Delta$. However, if the reserves is not sufficient to meet early demand, the bank crashes, making zero profit and those agents who wait get nothing. Those who withdraw early receive $r$ with probability $\frac{\rho}{\lambda r+(1-\lambda) \widetilde{\omega} r}$. The returns that agent $i$ (who is patient) would get can be summarised as follows:

\begin{tabular}{|l|l|l|}
\hline & $\lambda r+(1-\lambda) \widetilde{\omega} r \leq \rho$ & $\lambda r+(1-\lambda) \widetilde{\omega} r>\rho$ \\
\hline Withdraw early & $r$ & $r$ with probability $\frac{\rho}{\lambda r+(1-\lambda) \widetilde{\omega} r}$ \\
\hline Not withdraw early & $\frac{\delta(\theta-\lambda r-(\lambda r+\pi(1-\lambda))(\theta-1))}{(1+\delta)(1-\lambda)(1-\widetilde{\omega}(y))}$ & 0 \\
\hline
\end{tabular}

The difference in the expected utility of agent $i$ who received signal $\theta_{i}$ between withdrawing and not withdrawing in $t_{1}$ is given by:

$$
\begin{aligned}
g(\widehat{\theta}(\pi, \lambda))= & \int_{\theta_{i}-e}^{\widehat{\theta}+e-\frac{2 e \pi}{r}} \frac{1}{2 e} * \frac{\lambda r+(1-\lambda) \pi}{\lambda r+(1-\lambda) \widetilde{\omega}(y) r} u(r) d y+ \\
& +\int_{\widehat{\theta}+e-\frac{2 e \pi}{r}}^{\theta_{i}+e} \frac{1}{2 e} u(r) d y+ \\
& -\int_{\widehat{\theta}+e-\frac{2 e \pi}{r}}^{\theta_{i}+e} \frac{1}{2 e} * u\left(\delta \frac{((1-\lambda) \pi-(1-\lambda) * \widetilde{\omega}(y) r+(1-\rho) y)}{(1-\lambda)(1-\widetilde{\omega}(y))(1+\delta)}\right) d y .
\end{aligned}
$$

Proposition 8 There exists a unique point $\theta_{i}=\theta^{*}$ such that $g\left(\theta^{*}\right)=0$ where player $i$ is indifferent between withdrawing and not. 
Proof. Using equation (24), the expected utility from withdrawing is,

$$
g_{1}=\int_{\theta_{i}-e}^{\widehat{\theta}+e-\frac{2 e \pi}{r}} \frac{1}{2 e} * \frac{\lambda r+(1-\lambda) \pi}{\lambda r+(1-\lambda) \widetilde{\omega}(y) r} u(r) d y+\int_{\widehat{\theta}+e-\frac{2 e \pi}{r}}^{\theta_{i}+e} \frac{1}{2 e} u(r) d y,
$$

and the expected utility from not withdrawing is,

$$
g_{2}=\int_{\widehat{\theta}+e-\frac{2 e \pi}{r}}^{\theta_{i}+e} \frac{1}{2 e} * u\left(\delta \frac{(1-\lambda) \pi-(1-\lambda) * \widetilde{\omega}(y) r+(1-\rho) y}{(1-\lambda)(1-\widetilde{\omega}(y))(1+\delta)}\right) d y .
$$

We need to show that there is only one point $\theta_{i}=\theta^{*}$ where $g_{1}=g_{2}$.

First we look at the behaviour of $g_{2}$, which is the function that gives the expected utility of not withdrawing. $g_{2}=0$ for $\theta_{i} \leq \widehat{\theta}-\frac{2 e \pi}{r}$. When $\theta_{i} \geq \widehat{\theta}-\frac{2 e \pi}{r}, \frac{d g_{2}}{d \theta_{i}}>0, \frac{d^{2} g_{2}}{d \theta_{i}^{2}}$ $<0$ and therefore it is an increasing concave function.

Then we look at the function that gives the expected utility of withdrawing early. $g_{1}($.$) is fixed at \frac{\lambda r+(1-\lambda) \pi}{\lambda r+(1-\lambda) r} u(r)$ when $\theta_{i} \leq \widehat{\theta}-\frac{2 e \pi}{r}$. Then when $\widehat{\theta}-\frac{2 e \pi}{r} \leq \theta_{i} \leq \widehat{\theta}+2 e-\frac{2 e \pi}{r}$, it is an increasing concave function: $\frac{d g_{1}}{d \theta_{i}}>0, \frac{d^{2} g_{1}}{d \theta_{i}^{2}}<0$. However, it is fixed at $u(r)$ when $\theta_{i} \geq \widehat{\theta}+2 e-\frac{2 e \pi}{r}$.

Therefore we can conclude that $g_{1}=g_{2}$ only at one point and hence, there exists a unique point $\theta_{i}=\theta^{*}$ such that $g\left(\theta^{*}\right)=0$ where player $i$ is indifferent between withdrawing and not.

Lemma 1 below which is about $\theta^{*}$ is useful to prove the subsequent propositions. We find how $\theta^{*}$ changes with $\pi$ and $r$. This is useful because even though $\pi$ cannot be observed, in equilibrium, it can be predicted what the reserves would be.

Firstly, the lemma shows the obvious, that the probability of bank run increases with early return $r$. As early return increases, the agents have more incentive to withdraw in $t_{1}$.

Next it looks at what happens to the probability of bank runs at the point $\pi=0$. As explained earlier, $\rho \in[\lambda r, r]$. Therefore $\pi \geq 0$. What the lemma says is that the probability of a bank run goes down with $\pi$ when $\pi=0$. Therefore to minimises the probability of bank runs the bank needs to keep reserves over and above what is needed to cater to those who are hit by the liquidity shock. As discussed in the previous scenario, the existence of reserves will make the agents more confident that the bank will not crash.

If there is more reserves to face the early demand, the agents are confident that the bank will not crash in $t_{1}$. When $\pi=0$, the reserves are sufficient only to settle 


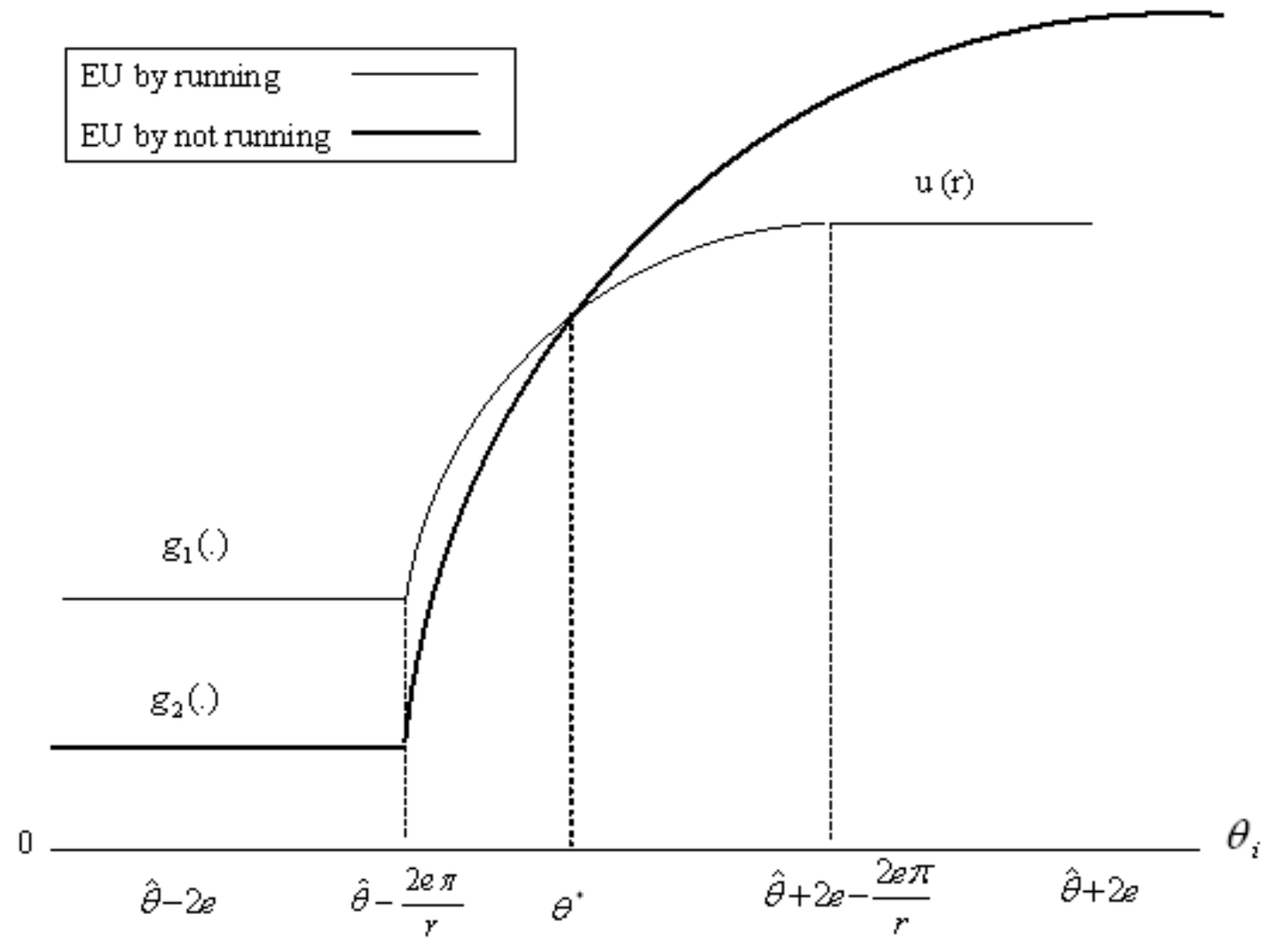

Figure 1: Threshold $\theta^{*}$. 
the demand of those who would be hit by the liquidity shock and definitely withdraw. This would make the agents very alert because even if one patient agent decides to withdraw, the bank would crash. Therefore the probability of a bank run is very high. Therefore as reserves get lower, getting closer to $\lambda r$, the threshold $\theta^{*}$ goes towards the upper dominant region.

Lemma 1 (1) $\frac{d \theta^{*}}{d r}>0$; (2) $\left.\frac{d \theta^{*}}{d \pi}\right|_{\pi=0}<0$; (3) $\operatorname{Lim}_{\pi \rightarrow 0} \theta^{*} \rightarrow \widetilde{\theta}$.

Proof. (1)

$$
\begin{aligned}
& g\left(\theta^{*}(\pi, r, \lambda)\right)= \int_{\theta^{*}-e}^{\theta^{*}+e-\frac{2 e \pi}{r}} \frac{1}{2 e} * \frac{\lambda r+(1-\lambda) \pi}{\lambda r+(1-\lambda) \widetilde{\omega}(y) r} u(r) d y+ \\
&+\int_{\theta^{*}+e-\frac{2 e \pi}{r}}^{\theta^{*}+e} \frac{1}{2 e} u(r) d y+ \\
&-\int_{\theta^{*}+e-\frac{2 e \pi}{r}}^{\theta^{*}+e} \frac{1}{2 e} * u\left(\frac{\delta(y-\lambda r-(\lambda r+\pi(1-\lambda))(y-1))}{(1+\delta)(1-\lambda)(1-\widetilde{\omega}(y))}\right) d y . \\
& \frac{d g}{d \theta^{*}}=\frac{1}{2 e}\left(\begin{array}{c}
-u\left(\frac{\delta\left(\theta^{*}+e-\lambda r-(\lambda r+\pi(1-\lambda))\left(\theta^{*}+e-1\right)\right)}{(1+\delta)(1-\lambda)}\right)+ \\
+u\left(\frac{\delta\left(\theta^{*}+e-\frac{2 e \pi}{r}-\lambda r-(\lambda r+\pi(1-\lambda))\left(\theta^{*}+e-\frac{2 e \pi}{r}-1\right)\right)}{(1+\delta)(1-\lambda)\left(1-\frac{\pi}{r}\right)}\right) \\
-\int_{\theta^{*}-e}^{\theta^{*}+e-\frac{2 e \pi}{r}}\left(\frac{(\lambda r+(1-\lambda) \pi)(1-\lambda) r}{2 e(\lambda r+(1-\lambda) \widetilde{\omega}(y) r)^{2}}\right) u(r) d y \\
-\int_{\theta^{*}+e-\frac{2 e \pi}{r}}^{\theta^{*}}(.) \frac{(\delta(y-\lambda r-(\lambda r+\pi(1-\lambda)(y-1))(1+\delta)(1-\lambda)}{2 e((1+\delta)(1-\lambda)(1-\widetilde{\omega}(y)))^{2}} d y
\end{array}\right)
\end{aligned}
$$

The first term in equation (28) is bigger than the second because it gives the utility at a higher value of $\theta$. Therefore on the whole $\frac{d g}{d \theta^{*}}<0$.

The first two terms in the function $g$ increase with $r$ whereas the last term goes down. Therefore on the whole, $\frac{d g}{d r}>0$.

Therefore $\frac{d \theta^{*}}{d r}>0$.

Q.E.D.

(2) Next we look at how $\theta^{*}$ changes with $\pi$ when $\pi$ is close to zero.

$$
\begin{aligned}
\frac{d g}{d \pi}= & \frac{1}{2 e} \int_{\theta^{*}-e}^{\theta^{*}+e-\frac{2 e \pi}{r}} \frac{(1-\lambda)}{\lambda r+(1-\lambda) \widetilde{\omega}(y) r} u(r) d y \\
& -\frac{1}{r} u\left(\frac{\delta\left(\theta^{*}+e-\frac{2 e \pi}{r}-\lambda r-(\lambda r+\pi(1-\lambda))\left(\theta^{*}+e-\frac{2 e \pi}{r}-1\right)\right)}{(1+\delta)(1-\lambda)\left(1-\frac{\pi}{r}\right)}\right) \\
& +\frac{1}{2 e} \int_{\theta^{*}+e-\frac{2 e \pi}{r}}^{\theta^{*}+e} \frac{u^{\prime}(.)(1-\lambda)(y-1)}{(1+\delta)(1-\lambda)(1-\widetilde{\omega}(y))} d y .
\end{aligned}
$$




$$
\begin{aligned}
\left.\frac{d g}{d \pi}\right|_{\pi=0}= & \frac{1}{2 e} \int_{\theta^{*}-e}^{\theta^{*}+e} \frac{(1-\lambda)}{\lambda r+(1-\lambda) \widetilde{\omega}(y) r} u(r) d y \\
& -\frac{1}{r} u\left(\frac{\delta\left(\theta^{*}+e-\lambda r-\lambda r\left(\theta^{*}+e-1\right)\right)}{(1+\delta)(1-\lambda)}\right) \\
& +\frac{1}{2 e} \int_{\theta^{*}+e}^{\theta^{*}+e} \frac{u^{\prime}(.)(1-\lambda)(y-1)}{(1+\delta)(1-\lambda)(1-\widetilde{\omega}(y))} d y .
\end{aligned}
$$

We have already shown in the first chapter that the first term in the above equation (30) is negative. The last term is now negligible. Therefore $\left.\frac{d g}{d \pi}\right|_{\pi=0}<0$, which means $\left.\frac{d \theta^{*}}{d \pi}\right|_{\pi=0}<0$.

Q.E.D.

(3) To prove this, we use the indifference condition given by $g($.$) .$

Recall equation (24).

$$
\begin{aligned}
g(\widehat{\theta}(\pi, \lambda))= & \int_{\theta_{i}-e}^{\widehat{\theta}+e-\frac{2 e \pi}{r}} \frac{1}{2 e} * \frac{\lambda r+(1-\lambda) \pi}{\lambda r+(1-\lambda) \widetilde{\omega}(y) r} u(r) d y+ \\
& +\int_{\widehat{\theta}+e-\frac{2 e \pi}{r}}^{\theta_{i}+e} \frac{1}{2 e} u(r) d y+ \\
& -\int_{\widehat{\theta}+e-\frac{2 e \pi}{r}}^{\theta_{i}+e} \frac{1}{2 e} * u\left(\delta \frac{((1-\lambda) \pi-(1-\lambda) * \widetilde{\omega}(y) r+(1-\rho) y)}{(1-\lambda)(1-\widetilde{\omega}(y))(1+\delta)}\right) d y
\end{aligned}
$$

When $\pi \rightarrow 0$, the last term and the second term are over a small range whereas the first term is over a larger range.

Therefore for $g\left(\theta^{*}\right)=0$ to hold, $\theta^{*}$ should be large, close to $\widetilde{\theta}$.

\section{Optimal Level of Reserves}

First we look at the bench mark, where the agents can observe the reserves. This is then compared with what the bank would choose when reserves cannot be observed by the agents.

\subsection{Benchmark when Reserves can be Observed}

If the level of reserves can be observed, the agents can work out their expected utility. Therefore, because the banks are in competition, the bank has to choose reserves to 
maximise the expected utility of the agents. When level of reserves is transparent, reserves would then be, $\rho^{t}=\lambda r+(1-\lambda) \pi^{t}$.

Because noise is very small, ex ante the probability of a partial run is negligible. If $\theta<\theta^{*}$ all the agents withdraw and receive $r$ with probability $\rho$. When $\theta>\theta^{*}$ the agents have $\lambda$ probability of being hit by a liquidity shock and receive $r$ while there is $(1-\lambda)$ probability that they receive $\frac{\delta \Delta}{1-\lambda}$.

$$
E U=\frac{1}{\bar{\theta}-\underline{\theta}}\left(\int_{\underline{\theta}}^{\theta^{*}} \rho u(r) d \theta+\int_{\theta^{*}}^{\bar{\theta}}\left(\lambda u(r)+(1-\lambda) u\left(\frac{\delta \Delta}{1-\lambda}\right)\right) d \theta\right) .
$$

Rearranging equation (31),

$$
E U=\frac{1}{\bar{\theta}-\underline{\theta}}\left(\int_{\underline{\theta}}^{\theta^{*}} \rho u(r) d \theta+\int_{\theta^{*}}^{\bar{\theta}}\left(\lambda u(r)+(1-\lambda) u\left(\frac{\delta(\theta-\lambda r-\rho(\theta-1))}{(1-\lambda)(1+\delta)}\right)\right) d \theta\right) .
$$

Proposition 9 When the level of reserves can be observed, the bank will choose $\rho^{t}>$ $\lambda r$.

Proof. We use equation (31) which gives the expected utility of an agent.

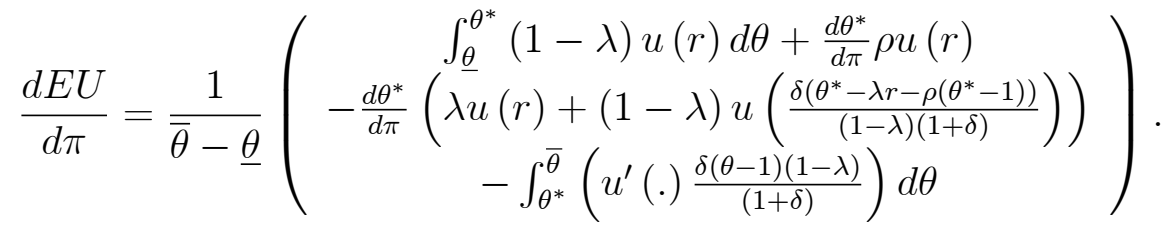

$$
\begin{aligned}
& \left.\frac{d E U}{d \pi}\right|_{\pi=0}=\frac{1}{\bar{\theta}-\underline{\theta}}\left(\begin{array}{c}
\theta^{*}(1-\lambda) u(r)+\frac{d \theta^{*}}{d \pi} \lambda r u(r) \\
-\frac{d \theta^{*}}{d \pi}\left(\lambda u(r)+(1-\lambda) u\left(\frac{\delta \theta^{*}(1-\lambda r)}{(1-\lambda)(1+\delta)}\right)\right) \\
-\int_{\theta^{*}}^{\bar{\theta}}\left(u^{\prime}(.) \frac{\delta(\theta-1)(1-\lambda)}{(1+\delta)}\right) d \theta
\end{array}\right) .
\end{aligned}
$$

We know that $\frac{d \theta^{*}}{d \pi}<0$. Further, $\lambda r u(r)<\left(\lambda u(r)+(1-\lambda) u\left(\frac{\delta \theta^{*}(1-\lambda r)}{(1-\lambda)(1+\delta)}\right)\right)$ and $\left.\theta^{*}\right|_{\pi=0} \rightarrow \widetilde{\theta}$

So we can conclude that $\left.\frac{d E U}{d \pi}\right|_{\pi=0}>0$, and therefore to maximise the expected utility of the agents, $\pi^{t}>0$.

This means $\rho^{t}>\lambda r$. 
When reserves can be observed, we are in the same situation as in scenario 1 where the expected utility of the agents has to be maximised. The finding is the same as before that the level of reserves should be over and above what is needed for those hit by the liquidity shock to maximise depositor welfare.

\subsection{When Reserves cannot be Observed}

Now we come to the main part of this analysis. When level of reserves cannot be observed, the agents cannot estimate their long term returns. Therefore when the reserves cannot be observed, the bank chooses level of reserves, $\rho^{*}$, to maximise its profit. Further, a proportion of the final profit is distributed to those who wait till $t_{2}$. The bank's objective is to maximise its expected profit, $E \Delta$.

If $\theta<\theta^{*}$ there will be a bank run and therefore the bank gets zero profit.

However if $\theta>\theta^{*}$, only proportion $\lambda$ agents withdraw and therefore it makes $\left(\rho-\lambda r+(1-\rho) \theta-\frac{(1-\lambda) \delta \Delta}{(1-\lambda)}\right)$.

$$
\begin{aligned}
\Delta & =0 & \text { if } \theta< \\
& =\frac{(1-\lambda) \pi+(1-\rho) \theta}{1+\delta} & \text { if } \theta>\theta^{*} .
\end{aligned}
$$

Therefore the ex ante expected profit $E \Delta$ for the bank is given by,

$$
E \Delta=\int_{\theta^{*}}^{\bar{\theta}} \frac{1}{\bar{\theta}-\underline{\theta}}\left(\frac{(1-\lambda) \pi+(1-\rho) \theta}{1+\delta}\right) d \theta .
$$

Proposition 10 When the level of reserves cannot be observed, the bank will choose optimal reserves, $\rho^{*}=\lambda r$, which is lower than when reserves could be observed.

Proof. The proof is very simple. Rearranging equation (34),

$$
E \Delta=\int_{\theta^{*}}^{\bar{\theta}} \frac{1}{\bar{\theta}-\underline{\theta}}\left(\frac{\theta-\lambda r \theta-\pi(1-\lambda)(\theta-1)}{1+\delta}\right) d \theta .
$$

Because $\pi$ cannot be observed by the agents, $\theta^{*}$ will not be affected by $\pi$.

$$
\frac{d E \Delta}{d \pi}=-\int_{\theta^{*}}^{\bar{\theta}} \frac{(1-\lambda)(\theta-1)}{(\bar{\theta}-\underline{\theta})(1+\delta)} d \theta<0 .
$$


Therefore the bank will choose $\pi^{*}=0$ to maximise profit - i.e. $\rho^{*}=\lambda r$.

According to proposition 9, when reserves could be observed, the bank would put aside $\rho^{t}>\lambda r$.

Therefore, $\rho^{*}<\rho^{t}$ which means when reserves cannot be observed, the bank keeps less reserves.

When the agents cannot observe the reserves that the bank keeps, it cannot increase the confidence of agents through reserves. Therefore it will keep reserves as low as possible. It will have to keep reserves to meet the demand of those hit by the liquidity shock who would definitely withdraw, otherwise the bank will collapse leaving the bank with no profits at all. Therefore, the bank will keep as reserves, just sufficient to meet that demand - i.e. $\rho^{*}=\lambda r$.

Consider the implications of this lower level of reserves on the probability of bank runs.

Proposition 11 When reserves cannot be observed, the probability of bank runs is higher.

Proof. The agents will choose $\theta^{*}$ knowing that $\pi^{*}=0$.

According to lemma $\left.1 \theta^{*}\right|_{\pi=0}$ will be close to the upper dominant region and $\frac{d \theta^{*}}{d \pi}<0$.

Therefore $\left.\theta^{*}\right|_{\pi^{*}=0}>\left.\theta^{*}\right|_{\pi^{t}>0}$ which means the probability of bank runs is higher when reserves cannot be observed.

Not only is the probability of bank runs higher, but obviously the expected utility of the agents is lower because the bank's objective is to maximise the expected utility.

This finding has policy implications. If the level of reserves cannot be observed, or if the agents are not informed to understand what is revealed, the regulators have a role to play. They can set reserve requirements that takes into consideration the welfare of the agents and make the agents aware that they are thus regulating. In countries where agents are able to comprehend such information, the regulators can make it a statutory requirement to make the level of reserves transparent.

\section{Early Return}

In this section we look at what happens if early return, $r$ is a choice variable. The bank is set in a competitive environment and since early return is observable, $r$ has 
to be chosen to maximise expected utility of depositors. When reserves cannot be observed, the bank would choose early return, $r^{*}$, given $\pi=0$. Is it any different from the early return that would be chosen if reserves was transparent, $r^{t}$ ?

Proposition 12 Early return when reserves cannot be observed, is higher than the early return when reserves is transparent. i.e. $r^{*}>r^{t}$.

Proof. Let the bank choose early return $r^{*}$ and $r^{t}$ when reserves are not transparent and transparent respectively. In both the cases, the early return is observable and the bank is in competition. Therefore it will choose early return to maximise the expected utility of the agents, $E U$.

Recall equation (32), giving $E U$,

$$
\begin{aligned}
& E U=\frac{1}{\bar{\theta}-\underline{\theta}}\left(\int_{\underline{\theta}}^{\theta^{*}} \rho u(r) d \theta+\int_{\theta^{*}}^{\bar{\theta}}\left(\lambda u(r)+(1-\lambda) u\left(\frac{\delta(\theta-\lambda r-\rho(\theta-1))}{(1-\lambda)(1+\delta)}\right)\right) d \theta\right) . \\
& \frac{d E U}{d r}=\frac{1}{\bar{\theta}-\underline{\theta}}\left(\begin{array}{c}
\frac{d \theta^{*}}{d r}(\lambda r+(1-\lambda) \pi) u(r) \\
+\int_{\underline{\theta}}^{\theta^{*}}\left(\lambda u(r)+(\lambda r+(1-\lambda) \pi) u^{\prime}(r)\right) d \theta \\
+\frac{d \theta^{*}}{d r}\left(\lambda u(r)-(1-\lambda) u\left(\frac{\delta\left(\theta^{*}-\lambda r-(\lambda r+\pi(1-\lambda))\left(\theta^{*}-1\right)\right)}{(1-\lambda)(1+\delta)}\right)\right) \\
+\int_{\theta^{*}}^{\bar{\theta}}\left(\lambda u^{\prime}(r)-\left(\frac{\lambda \delta \theta}{(1+\delta)}\right) u^{\prime}\left(\frac{\delta\left(\theta^{*}-\lambda r-(\lambda r+\pi(1-\lambda))\left(\theta^{*}-1\right)\right)}{(1-\lambda)(1+\delta)}\right)\right) d \theta
\end{array}\right)
\end{aligned}
$$

When reserves cannot be observed, the bank will choose $\pi^{*}=0$.

$$
\left.\frac{d E U}{d r}\right|_{\pi=0}=\frac{1}{\bar{\theta}-\underline{\theta}}\left(\begin{array}{c}
\int_{\underline{\theta}}^{\theta^{*}}\left(\lambda u(r)+\lambda r u^{\prime}(r)\right) d \theta+ \\
-(1-\lambda) \frac{d \theta^{*}}{d r} u\left(\frac{\delta \theta^{*}(1-\lambda r)}{(1-\lambda)(1+\delta)}\right) \\
+\int_{\theta^{*}}^{\bar{\theta}}\left(\lambda u^{\prime}(r)-\left(\frac{\lambda \delta \theta}{(1+\delta)}\right) u^{\prime}\left(\frac{\delta \theta(1-\lambda r)}{(1-\lambda)(1+\delta)}\right)\right) d \theta
\end{array}\right)
$$

According to lemma $1, \theta^{*} / \pi=0 \rightarrow \widetilde{\theta}$. Therefore the last term in equation (16) is negligible. The first term is significant. The second term is the late return at one point, $\theta^{*}$ whereas the first term is over the whole range $\left(\underline{\theta}, \theta^{*}\right)$. When $\theta^{*}$ is large, $\frac{d \theta^{*}}{d r}$ will be small (threshold $\theta^{*}$ cannot increase more than $\widetilde{\theta}$ which makes $\frac{d \theta^{*}}{d r}$ negligible). 
Further, we prove below that $r^{*}>1$.

$$
\begin{gathered}
\left.\frac{d E U}{d r}\right|_{\pi=0, r=1}=\frac{1}{\bar{\theta}-\underline{\theta}}\left(\begin{array}{c}
\int_{\underline{\theta}}^{\theta^{*}} 2 \lambda d \theta+ \\
-(1-\lambda) \frac{d \theta^{*}}{d r} u\left(\frac{\delta \theta^{*}}{(1+\delta)}\right) \\
+\lambda \alpha \int_{\theta^{*}}^{\bar{\theta}}\left(1-\left(\frac{\delta \theta}{(1+\delta)}\right)^{\alpha}\right) d \theta
\end{array}\right) . \\
\theta^{*}>u\left(\theta^{*}\right) \Leftrightarrow \theta^{*}>u\left(\frac{\delta \theta^{*}}{(1+\delta)}\right) \Leftrightarrow 2 \lambda \theta^{*}>(1-\lambda) u\left(\frac{\delta \theta^{*}}{(1+\delta)}\right) \\
\Leftrightarrow 2 \lambda \theta^{*}>(1-\lambda) \frac{d \theta^{*}}{d r} u\left(\frac{\delta \theta^{*}}{(1+\delta)}\right) .
\end{gathered}
$$

If we fix $\underline{\theta}=0$,

$\int_{\underline{\theta}}^{\theta^{*}} 2 \lambda d \theta+\lambda \alpha \int_{\theta^{*}}^{\bar{\theta}}\left(1-\left(\frac{\delta \theta}{(1+\delta)}\right)^{\alpha}\right) d \theta>(1-\lambda) \frac{d \theta^{*}}{d r} u\left(\frac{\delta \theta^{*}}{(1+\delta)}\right)$.

Therefore $\left.\frac{d E U}{d r}\right|_{\pi=0, r=1}>0$ which means $r^{*}>1$.

Now we look at the bench mark model where reserves can be observed and $\pi$ and $r$ are chosen to maximise the $E U$. When reserves can be observed, the bank would choose $\pi^{t}>0$.

$$
\left.\frac{d E U}{d r}\right|_{r=1}=\frac{1}{\bar{\theta}-\underline{\theta}}\left(\begin{array}{c}
\frac{d \theta^{*}}{d r}(1-\lambda)\left(-u\left(\frac{\delta\left(\theta^{*}-\lambda-(\lambda+\pi(1-\lambda))\left(\theta^{*}-1\right)\right)}{(1-\lambda)(1+\delta)}\right)+\pi\right) \\
+(\pi \alpha(1-\lambda)+\lambda(1+\alpha))\left(\theta^{*}-\underline{\theta}\right) \\
-\int_{\theta^{*}}^{\bar{\theta}}\left(\lambda \alpha+u^{\prime}(.)\left(\frac{\delta \lambda \theta^{*}}{(1+\delta)}\right)\right) d \theta
\end{array}\right)
$$

The first and last terms are negative. Only the second term is positive, which is negligible compared to the others.

Therefore $\left.\frac{d E U}{d r}\right|_{\pi>0, r=1}<0$ so that we can conclude that $r^{t}<1$.

This means that if the level of reserves was transparent, the bank will choose an early return that is less than one, which is lower than what it would choose when reserves cannot be observed.

The bank, which operates in a competitive environment chooses an early return, which is observable, that is high in order to attract customers. It is also noteworthy that according to lemma 1 , because $\frac{d \theta^{*}}{d r}>0$, when reserves cannot be observed, the banks would choose an early return that increases the probability of bank runs, compared to when the level of reserves was transparent. As in the case of optimal reserves, this also gives a lower expected utility.

Therefore when level of reseres cannot be observed, the regulators have another role to play, which is to control the early return $r$ that the banks offer. 


\section{Conclusion}

We have a model of bank runs using a global game framework in an attempt to find out how much reserves a bank should keep and what is the early return it should offer to maximise the expected utility of the depositors. The analysis was done under two scenarios, namely, when the level of reserves could be observed by the depositors, and when it could not be.

Under the first situation, it is found that both the optimal reserves and early returns should be increasing with the proportion of impatient agents and decreasing with the earning capacity of the bank. It is also found that compared to the first-best case, the optimal early return is lower. Another interesting result is that in addition to those who are hit by the liquidity shock, others also might withdraw early, and therefore reserves was found to be more than what was needed to cater to the impatient agents. This inefficiency increases with the proportion of impatient agents. We also find that maximum expected utility to depositors requires a positive probability of bank runs.

Policy makers should take note that if banks are operating in a competitive environment where the agents can observe reserves, the bank would voluntarily choose reserves to maximise the expected utility of depositors. Therefore there is no need for reserve requirements, however it should be ensured that reserves are made known and there is a competitive environment. Giving insurance to early withdrawers is not healthy.

The second scenario looked at whether there would be a need for regulation if the level of reserves was not transparent. The answer was found to be in the affirmative. It was found that when the level of reserves cannot be observed, the bank chooses a level of reserves that is too low and chooses early return that is too high. This not only lowers the welfare of the depositors but also creates financial instability by increasing the probability of bank runs. Therefore when the level of reserves cannot be observed, the regulators do have a role to play in fixing minimum reserve requirement and maximum early return that the banks could choose. 


\section{A Appendix}

\section{A.1 Proof of Proposition 1}

Recall equation 1 which gives the difference in the expected utility of agent $i$ who received signal $\theta_{i}$ between withdrawing and not withdrawing.

$$
\begin{aligned}
g\left(\theta_{i}(r, \pi, \lambda)\right)= & \int_{\theta_{i}-e}^{\widehat{\theta}+e-\frac{2 e \pi}{r}} \frac{1}{2 e} * \frac{\rho}{\lambda r+(1-\lambda) \widetilde{\omega}(y) r} u(r) d y \\
& +\int_{\widehat{\theta}+e-\frac{2 e \pi}{r}}^{\theta_{i}+e} \frac{1}{2 e} u(r) d y+ \\
& -\int_{\widehat{\theta}+e-\frac{2 e \pi}{r}}^{\theta_{i}+e} \frac{1}{2 e} * u\left(\frac{\rho-\lambda r-(1-\lambda) * \widetilde{\omega}(y) * r+(1-\rho) y}{(1-\lambda)(1-\widetilde{\omega}(y))}\right) d y
\end{aligned}
$$

$g: R \rightarrow R$

Because of the lower dominant region, $\underset{\theta_{i} \rightarrow \underline{\theta}}{\operatorname{Lim}} g\left(\theta_{i}\right)>0$ so that if an agent receives a signal $\underline{\theta}$, he will withdraw. On the other hand, because of the upper dominant region,

$\operatorname{Lim}_{\theta_{i} \rightarrow \bar{\theta}} g\left(\theta_{i}\right)<0$ so that an agent who receives a signal $\bar{\theta}$ will not withdraw. This is because the expected return from not withdrawing is very high.

Therefore, as long as the function is continuous a value exists for $\theta_{i}$ such that $g\left(\theta^{*}, \widehat{\theta}\right)=0$. Because of symmetry, all agents are indifferent between withdrawing early and not doing so when they receive a signal $\theta^{*}$.

The expected utility of withdrawing early is continuous. When $\theta_{i} \leq \widehat{\theta}-2 e, \widetilde{\omega}(y)=$ $1 \forall y$. This means we have a constant expected utility, $\left(\lambda+(1-\lambda) \frac{\pi}{r}\right) u(r)$. When $\theta_{i} \geq \widehat{\theta}+2 e, \widetilde{\omega}(y)=0 \forall y$ giving a constant expected utility of $u(r)$. In between the expected utility continuously increases.

The expected utility of not withdrawing early is zero for $\theta_{i} \leq \widehat{\theta}-\frac{2 e \pi}{r}$. After that, it increases continuously. Therefore the function $g($.$) is continuous in \theta_{i}$.

Now we show that the point where $g\left(\theta^{*}, \widehat{\theta}\right)=0$ is unique.

Please refer to figures at the end.

For the range $\theta_{i} \leq \widehat{\theta}-2 e, \widetilde{\omega}(y)=1 \forall y$. The expected utility of not running is zero. This means we have a constant $\left.g()\right|_{.\left(\theta_{i} \leq \widehat{\theta}-2 e\right)}=\frac{\rho}{\lambda r+(1-\lambda) r} u(r)>0$. 
For the range $\widehat{\theta}-2 e \leq \theta_{i} \leq \widehat{\theta}-\frac{2 e \pi}{r}, \widetilde{\omega}$ is high enough that you receive nothing by waiting.

$$
\begin{aligned}
\left.g(.)\right|_{\left(\widehat{\theta}-2 e \leq \theta_{i} \leq \widehat{\theta}-\frac{2 e \pi}{r}\right)}= & \int_{\theta_{i}-e}^{\widehat{\theta}-e} \frac{1}{2 e} * \frac{\rho}{\lambda r+(1-\lambda) r} u(r) d y+ \\
& +\int_{\widehat{\theta}-e}^{\theta_{i}+e} \frac{1}{2 e} * \frac{\rho}{\lambda r+(1-\lambda) \widetilde{\omega}(y) r} u(r) d y .
\end{aligned}
$$

It is clear that $\left.g()\right|_{.\left(\widehat{\theta}-2 e \leq \theta_{i} \leq \widehat{\theta}-\frac{2 e \pi}{r}\right)}>0$.

Furthermore in this range, as $\theta_{i}$ increases, the expected proportion of those wanting to withdraw goes down. i.e. the expected utility of running continuously increases with $\theta_{i}$

$$
\frac{d g(.)}{d \theta_{i}} /_{\left(\widehat{\theta}-2 e \leq \theta_{i} \leq \widehat{\theta}-\frac{2 e \pi}{r}\right)}=\frac{1}{2 e}\left(\frac{\rho}{\lambda r+(1-\lambda)\left(\frac{\widehat{\theta}-\theta_{i}+2 e}{2 e}\right) r}-\frac{\rho}{\lambda r+(1-\lambda) r}\right) u(r) .
$$

We know that $\frac{\widehat{\theta}-\theta_{i}+2 e}{2 e}<1$. Therefore $\left.\frac{d g(.)}{d \theta_{i}}\right|_{\left(\widehat{\theta}-2 e \leq \theta_{i} \leq \widehat{\theta}-\frac{2 e \pi}{r}\right)}>0$.

For the range, $\widehat{\theta}+2 e-\frac{2 e \pi}{r} \leq \theta_{i} \leq \widehat{\theta}+2 e, \widetilde{\omega}(y) \leq \frac{\pi}{r} . \forall y$. Therefore the bank is expected not to crash $\forall y$. Those who withdraw early will receive $r$ for sure. By waiting the agent $i$ 's expected utility is $\int_{\theta_{i}-e}^{\theta_{i}+e} \frac{1}{2 e}\left(u\left(\pi+\frac{(1-\rho) y}{(1-\lambda)(1-\widetilde{\omega}(y))}\right)\right) d y$.

$$
\left.g(.)\right|_{\left(\widehat{\theta}+2 e-\frac{2 e \pi}{r} \leq \theta_{i} \leq \widehat{\theta}+2 e\right)}=u(r)-\int_{\theta_{i}-e}^{\theta_{i}+e} \frac{1}{2 e}\left(u\left(\pi+\frac{(1-\rho) y}{(1-\lambda)(1-\widetilde{\omega}(y))}\right)\right) d y .
$$

In this range bank will not crash. i.e. $r$ is low enough to make the reserves sufficient to cater to early demand. If early withdrawal is better than not withdrawing, everyone will definitely withdraw prompting the bank to crash. The fact that the bank does not crash in the range tells us that when $\widehat{\theta}+2 e-\frac{2 e \pi}{r} \leq \theta_{i} \leq \widehat{\theta}+2 e$, we have $u(r) \leq \int_{\theta_{i}-e}^{\theta_{i}+e} \frac{1}{2 e}\left(u\left(\frac{(1-\lambda)(\pi-\omega)+(1-\rho) y}{(1-\lambda)(1-\omega(y))}\right)\right) d y$.

Therefore $g() /.\left(\widehat{\theta}+2 e-\frac{2 e \pi}{r} \leq \theta_{i} \leq \widehat{\theta}+2 e\right)<0$.

Also note that in this range, when $\theta_{i}$ increases, the expected utility of running does not change, but remains at $u(r)$. However the expected utility of waiting increases 
with $\theta_{i}$.

$$
\frac{d g(.)}{d \theta_{i}} /\left(\widehat{\theta}+2 e-\frac{2 e \pi}{r} \leq \theta_{i} \leq \widehat{\theta}+2 e\right)=-\frac{1}{2 e}\left(\begin{array}{c}
u\left(\pi+\frac{(1-\rho)\left(\theta_{i}+e\right)}{(1-\lambda)\left(1-\frac{\widehat{\theta}-\theta_{i}}{2 e}\right)}\right) \\
-u\left(\pi+\frac{(1-\rho)\left(\theta_{i}-e\right)}{(1-\lambda)\left(1-\frac{\widehat{\theta}-\theta_{i}+2 e}{2 e}\right)}\right)
\end{array}\right) .
$$

It is obvious that the utility when $y=\theta_{i}+e$ is greater than the utility when $y=\theta_{i}-e$.

Therefore $\left.\frac{d g(.)}{d \theta_{i}}\right|_{\left(\widehat{\theta}+2 e-\frac{2 e \pi}{r} \leq \theta_{i} \leq \widehat{\theta}+2 e\right)}<0$.

For the range, $\theta_{i} \geq \widehat{\theta}+2 e, \widetilde{\omega}(y)=0 \forall y$. This means,

$$
\left.g(.)\right|_{\left(\theta_{i} \geq \widehat{\theta}+2 e\right)}=u(r)-\int_{\theta_{i}-e}^{\theta_{i}+e} \frac{1}{2 e}\left(u\left(\pi+\frac{(1-\rho) y}{1-\lambda}\right)\right) d y .
$$

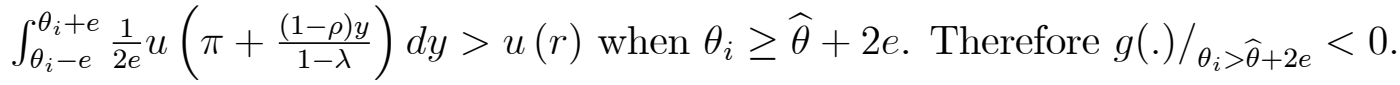

Furthermore

$$
\begin{gathered}
\left.\frac{d g(.)}{d \theta_{i}}\right|_{\theta_{i} \geq \widehat{\theta}+2 e}=-u\left(\pi+\frac{(1-\rho)\left(\theta_{i}+e\right)}{1-\lambda}\right)+u\left(\pi+\frac{(1-\rho)\left(\theta_{i}-e\right)}{1-\lambda}\right) . \\
\left.\frac{d g(.)}{d \theta_{i}}\right|_{\theta_{i} \geq \widehat{\theta}+2 e}<0 \text { because } u\left(\pi+\frac{(1-\rho)\left(\theta_{i}+e\right)}{1-\lambda}\right)>u\left(\pi+\frac{(1-\rho)\left(\theta_{i}-e\right)}{1-\lambda}\right) .
\end{gathered}
$$

We can now conclude that, if there is a point at which $g()=$.0 , it will be in the range $\widehat{\theta}-\frac{2 e \pi}{r} \leq \theta_{i} \leq \widehat{\theta}+2 e-\frac{2 e \pi}{r}$.

We have to check there is only one such point.

This is so if in this range the function $g($.$) is concave. In this range the function$ $g($.$) can be split into two parts: \widehat{\theta}-\frac{2 e \pi}{r} \leq \theta_{i} \leq \widehat{\theta}$ and $\widehat{\theta} \leq \theta_{i} \leq \widehat{\theta}+2 e-\frac{2 e \pi}{r}$.

In the range $\widehat{\theta}-\frac{2 e \pi}{r} \leq \theta_{i} \leq \widehat{\theta}$, where

$$
\begin{aligned}
\left.g(.)\right|_{\left(\widehat{\theta}-\frac{2 e \pi}{r} \leq \theta_{i} \leq \widehat{\theta}\right)}= & \int_{\theta_{i}-e}^{\widehat{\theta}-e} \frac{1}{2 e} *\left(\lambda+(1-\lambda) \frac{\pi}{r}\right) u(r) d y+ \\
& +\int_{\widehat{\theta}-e}^{\widehat{\theta}_{-} \frac{2 e \pi}{r}} \frac{1}{2 e} * \frac{\rho}{\lambda * r+(1-\lambda) * \widetilde{\omega}(y) * r} u(r) d y \\
& +\int_{\widehat{\theta}-\frac{2 e \pi}{r}}^{\theta_{i}+e} \frac{1}{2 e} u(r) d y \\
& -\int_{\widehat{\theta}-\frac{2 e \pi}{r}}^{\theta_{i}+e} \frac{1}{2 e} * u\left(\pi+\frac{(1-\lambda)(\pi-\omega)+(1-\rho) y}{(1-\lambda)(1-\widetilde{\omega})}\right) d y .
\end{aligned}
$$




$$
\begin{gathered}
\left.\frac{d g}{d \theta_{i}}\right|_{\widehat{\theta}-\frac{2 e \pi}{r} \leq \theta_{i} \leq \widehat{\theta}}=\frac{1}{2 e}\left(\begin{array}{c}
u(r)(1-\lambda)\left(1-\frac{\pi}{r}\right) \\
-u\left(\pi+\frac{(1-\lambda)\left(\pi-\frac{\widehat{\theta}-\theta_{i}}{2 e} r\right)+(1-\rho)\left(\theta_{i}+e\right)}{(1-\lambda)\left(1-\frac{\widehat{\theta}-\theta_{i}}{2 e}\right)}\right)
\end{array}\right) . \\
\frac{d^{2} g}{d \theta_{i}^{2}} / \widehat{\theta}-\frac{2 e \pi}{r} \leq \theta_{i} \leq \widehat{\theta} \\
=-\frac{1}{2 e} u^{\prime}(.) \frac{(1-\lambda)\left(\frac{r-\pi}{2 e}\right)+(1-\rho)}{(1-\lambda)\left(\frac{1-\widehat{\theta}-\theta_{i}}{2 e}\right)^{2}}<0 .
\end{gathered}
$$

Therefore in the range $\widehat{\theta}-\frac{2 e \pi}{r} \leq \theta_{i} \leq \widehat{\theta}, g($.$) is concave.$

In the range $\widehat{\theta} \leq \theta_{i} \leq \widehat{\theta}+2 e-\frac{2 e \pi}{r}$, where

$$
\begin{aligned}
\left.g(.)\right|_{\left(\widehat{\theta} \leq \theta_{i} \leq \widehat{\theta}+2 e-\frac{2 e \pi}{r}\right)}= & \int_{\theta_{i}-e}^{\widehat{\theta}+e-\frac{2 e \pi}{r}} \frac{1}{2 e} * \frac{\rho}{\lambda r+(1-\lambda) \widetilde{\omega} r} u(r) d y \\
& +\int_{\widehat{\theta}+e-\frac{2 e \pi}{r}}^{\theta_{i}+e} \frac{1}{2 e} * u(r) d y \\
& -\int_{\widehat{\theta}+e-\frac{2 e \pi}{r}}^{\theta_{i}+e} \frac{1}{2 e} * u\left(\pi+\frac{(1-\lambda)(\pi-\widetilde{\omega})+(1-\rho) y}{(1-\lambda)(1-\widetilde{\omega})}\right) d y . \\
\left.\frac{d g}{d \theta_{i}}\right|_{\left(\widehat{\theta} \leq \theta_{i} \leq \widehat{\theta}+2 e-\frac{2 e \pi}{r}\right)} & \frac{1}{2 e}\left(\frac{(1-\lambda)\left(\frac{\widehat{\theta}-\theta_{i}}{2 e} r+r-\pi\right)}{\lambda r+(1-\lambda)\left(\frac{\widehat{\theta}-\theta_{i}}{2 e}+1\right) r}\right) u(r) \\
& -\frac{1}{2 e} u\left(\pi+\frac{(1-\lambda)\left(\pi-\frac{\widehat{\theta}-\theta_{i}}{2 e} r\right)+(1-\rho)\left(\theta_{i}+e\right)}{(1-\lambda)\left(1-\frac{\widehat{\theta}-\theta_{i}}{2 e}\right)}\right) .(52)
\end{aligned}
$$

In this range, as $\theta_{i}$ increases, the expected returns from running increases with $\theta_{i}$ which is given by the first term.. This is because now the range over which you surely receive $r$ increases and the probability of receiving $r$ increases. Let this term be A. This increases at a decreasing rate. The second term refers to the expected returns from not running which increases with $\theta_{i}$. Let this be $\mathrm{B}$. This increase is at an increasing rate.

$$
\left.\frac{d^{2} g}{d \theta_{i}^{2}}\right|_{\left(\widehat{\theta} \leq \theta_{i} \leq \widehat{\theta}+2 e-\frac{2 e \pi}{r}\right)}=\frac{d A}{d \theta_{i}}-\frac{d B}{d \theta_{i}}<0 .
$$




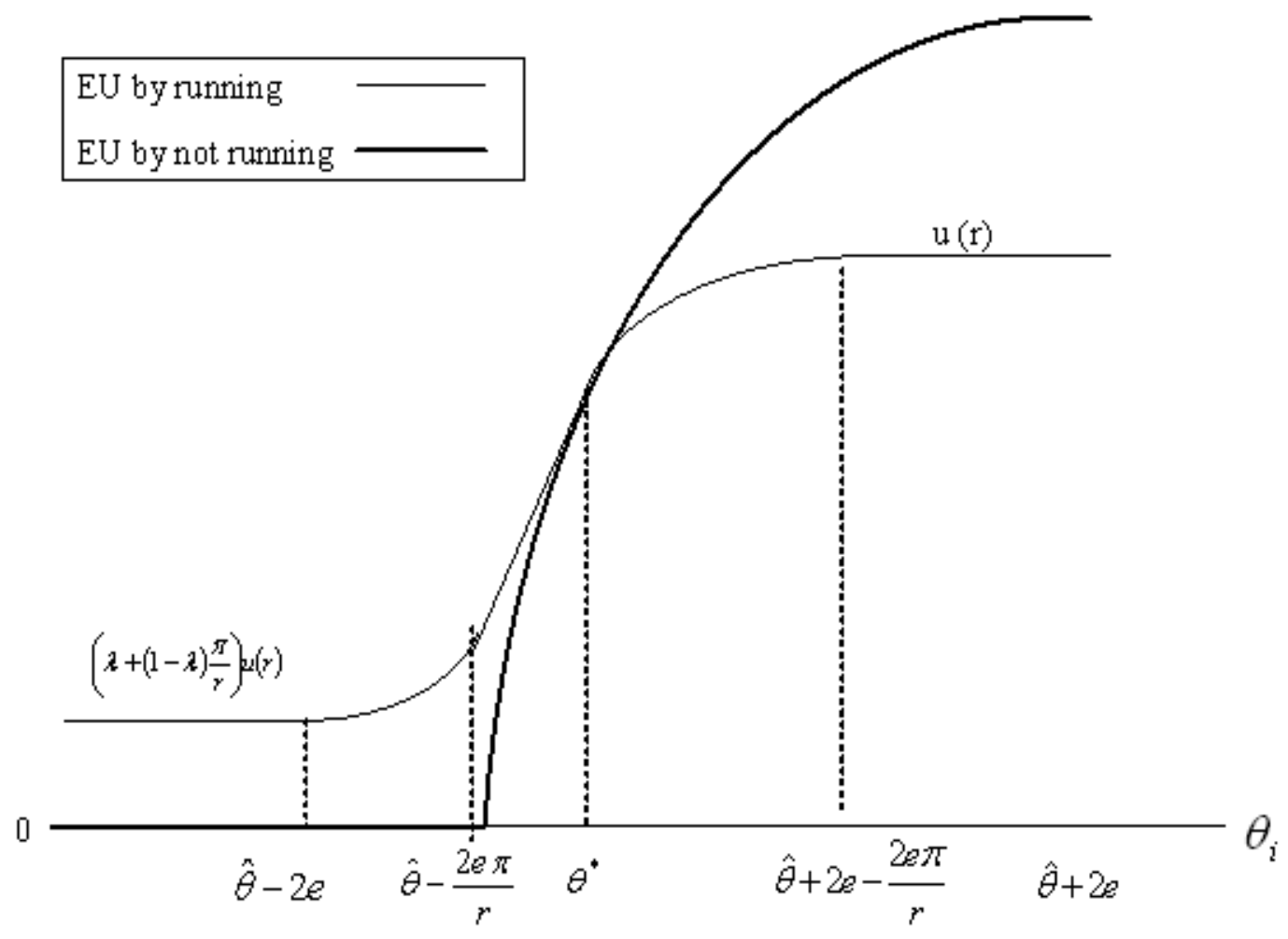

Figure 2: EU of running and not running with $\theta_{i}$

Therefore we can conclude that there exists a unique $\theta^{*}$ such that above which, $g<0$ and below which, $g>0$ and thereby a patient agent would not withdraw if $\theta_{i}>\theta^{*}$ and would withdraw if $\theta_{i}<\theta^{*}$.

Q.E.D. 


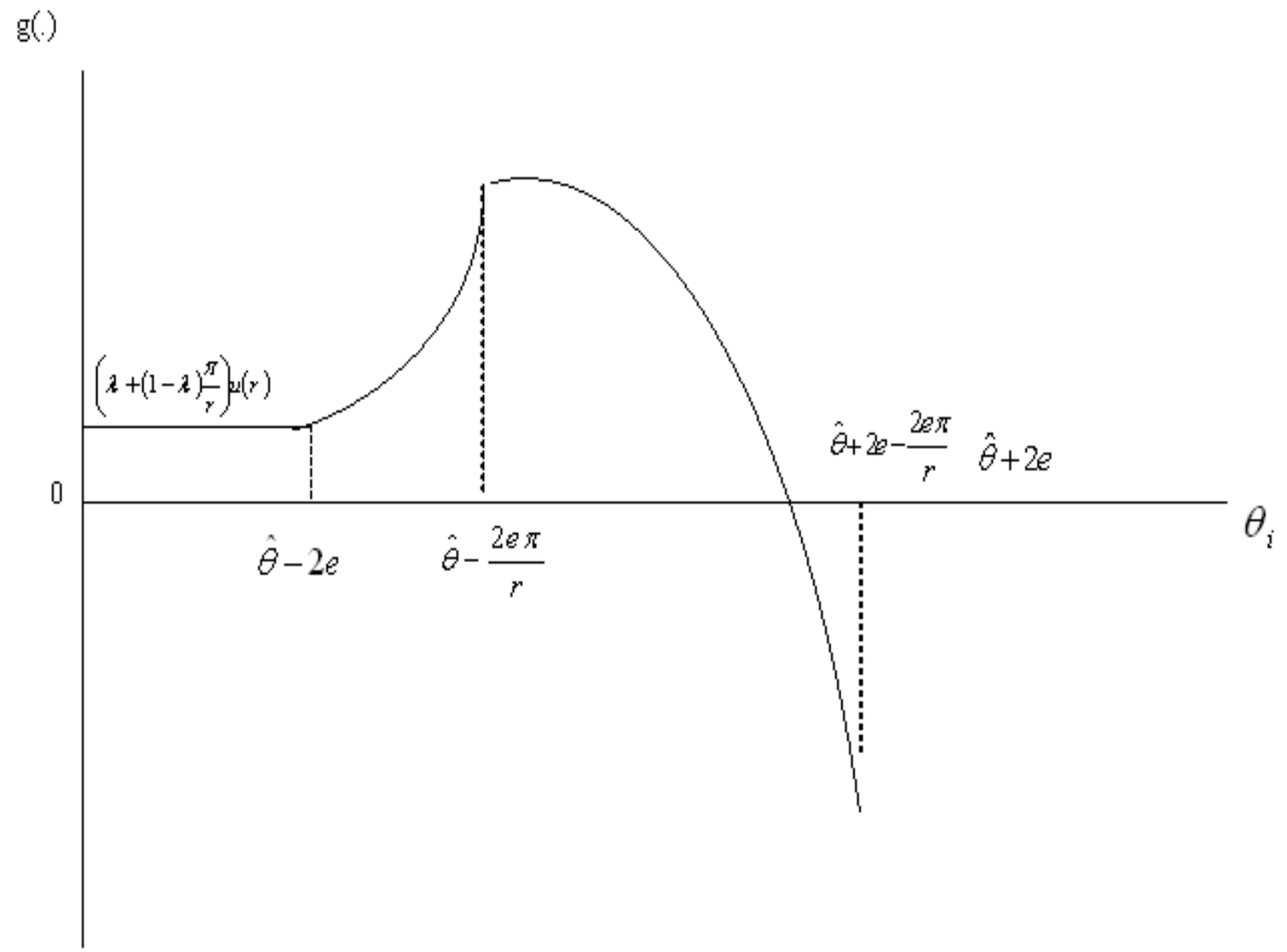

Figure 3: Threshold $\theta^{*}$. 


\section{References}

Alonso, I., 1996. On avoiding bank runs. Journal of Monetary Economics. 37, 73 87.

Bougheas, S., 1999. Contagious Bank runs. International Review of Economics and Finance. 8, 131 - 146.

Byrant, J., 1980. A model of reserves, bank runs and deposit insurance. Journal of Banking and Finance. 4, 335 - 344.

Bernardo, A. E., I, Welch., 2004. Liquidity and financial market runs. Quarterly Journal of Economics. Forthcoming.

Bhattacharya, S., Boot, A. W. A., Thakor, A. V., 1998. The economics of bank regulation. Journal of Money, Credit and Banking. 30(4), 745-770.

Carlsson, H., E. van Damme., 1993. Global games and equilibrium selection. Econometrica. $61,989-1018$.

Chari, V. V., Jegannathan, R., 1988. Banking panics, information and rational expectations equilibrium. Journal of Finance. 43, 749 - 760.

Clouse, J. A., Dow Jr., J. P., 2002. A computational model of banks' optimal reserve management policy. Journal of Economic Dynamics and Control. 26, 1787 1814.

Cooper, R., Ross, T. W., 1998. Bank Runs: Liquidity costs and investment distortions. Journal of Monetary Economics. 41, 27 - 38.

Cothren, R., 1987. Asymmetric information and optimal bank reserves. Journal of Money Credit and Banking. 19(1), 68 - 77.

Demirguc-Kunt, A., Detragiache, E., 1998. The determinants of banking crisis: evidence from developed and developing countries. International Monetary Fund Staff papers. 45, $81-109$.

Diamond, D.W., Dybvig, P. H., 1983. Bank runs, deposit insurance, and liquidity. Journal of Political Economy. 91, 401 - 419. 
Goldstein, I., Pauzner, A., 1995. Demand deposit contracts and the probability of bank runs. Journal of Finance. 1293-1327.

Gorton, G., 1985. Bank Suspension and Convertibility. Journal of Monetary Economics. $15(2), 177$ - 193.

Gorton, G., 1988. Banking panics and business cycles. Oxford Economics Papers. $40,751-781$.

Jacklin, C. J., Bhattacharya, S., 1988. Distinguishing pnics and information based bank runs: welfare and policy implications. Journal of Political Economy. 96, $568-592$.

Loewy, M. B., 1998. Information based bank runs in a monetary economy. Journal of Macroeconomics. 20, $681-702$.

Morris, S., Shin, H. S., 1998. Unique equilibrium in a model of self-fulfilling currency attacks. American Economic Review. 88, 587-597.

Morris, S., Shin, H. S., 2002. Global games: theory and applications. Advances in Economics and Econometrics, the Eighth World Congress. Edited by Cambridge University Press.

Peck, J., K, Shell., 2003. Equilibrium bank runs. Journal of Political Economy. 111, $103-123$.

Radelet, S., Sachs, J. D., 1998. The East Asian financial crisis: diagnosis, remedies, prospects. Brookings Papers on Economic Activity. 1, $1-74$.

Ringbom, S., Shy, O., Stenbacka R., 2004. Optimal liquidity management and bailout policy in the banking industry. Journal of Banking and Finance. 28, 1319 1335. 